\title{
خطة مقترحة لتحسين أساليب التمويل بالمنشأت الرياضية بمحافظات جنوب
}

\section{الصعيد}

\section{الباحث/ علاء حامد عبد الظاهر محمد}

أصبحت الإدارة المعاصرة تعرف كحركة فكرية سريعة على خلاف العصور

السابقة، ولا زالت تتظور وتتجه إلى زيادة الاهتمام بالموارد البشرية لتغيير دوره داخل التنظيم ومن جانب آخر زيادة دورة المعرفة والمعلومات في أداء الأنشطة وزيادة استخدام وسائل تكنولوجيا المعلومات والإتصال في إتمام العمل الإداري وخصائص

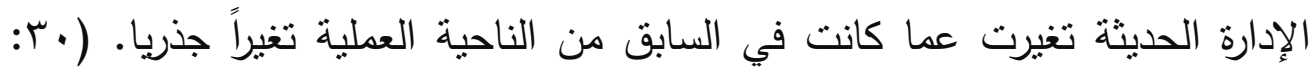

ويساعد التمويل المالي الأندية الرياضية على تحقيق أهدافها، إذ أنه لن تتحقق سبل النجاح لهذه الأندية إلا إذا تم توفير الموارد المالية اللازمة لإدارة أنشطتها ومن ثم تحقيق الأهداف المرجوة، لذا يجب عليها أن تعد لنفسها خطة تمويلية سليمة تتضمن توفير القدر الكافى من حجم ومصادر رأس المال التى تتيح لها إتخاذ قراراتها

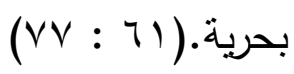

وتعد الصعوبات المالية التي تواجه الرياضة بمصر تتمثل فيما يلي: الاعتماد الكلي على الدعم الحكومي وقلة مصادر التمويل الذاتي، وضعف فرص الإستثمار للأموال والمنشآت الرياضية، وضعف فرص الملكية الخاصة للهيئات الرياضية، إستمرار سيطرة الدولة علي أوجه وأثكال التمويل للهيئات الرياضية من خلال سيطرتها علي إثارة البث التليفزيوني لنقل الأحداث الرياضية علي القنوات الأرضية بإعتبار عائد البث التلبفزيوني أحد أهم المصادر المباشرة للهيئات الرياضية في زيادة مواردها من التمويل الذاتي، والتحكم المركزي في الهيئات الرياضية من خلا الجهة الحكومية المسئولة عن الرياضة التي تعتبر المرجع الأول والأخير لتتفيذ قرارات الهيئات الرياضية، وخاصة 
القرارات المالية والتي تدير جميع أنشطة الثباب والرياضة، وعدم إطلاق العنان والحرية للهيئات الرياضية في إستثمار وتنويق أموالها ومنشأنها.(1)

وظهر التمويل وتطور بشكل ملحوظ وكان ضرورياً للتغلب على التحديات المختلفة التى تواجهها الأعمال الاستثمارية، مما يدفع المستثمرين ورجال الأعمال إلى البحث

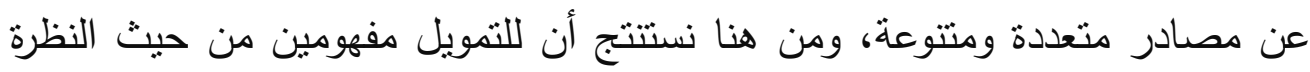
الضيقة، تعنى كلمة التمويل مجموعة وسائل الاقتراض التى تعنى للمؤسسة أستمرار نشاطها، أما من خلال النظرة الواسعة للتمويل هو مجمل العمليات التى من خلالها تقوم المؤسسة بنلبية كل منطلباتها من أموال وزيادات لاحقة للعقود، القروض بصفة لهنة عامة أو المنشآت أو المساهمة الممنوحة بسندات باهظة أو تطوعية من طرق الدولة، الخزينة العامة، الجماعات المحلية.(19 : والتمويل في المجال الرياضى هو عبارة عن عملية البحث عن موارد مادية للإنفاق على الأنشطة الرياضية وله ثلاث مصادر أساسية هي التمويل الحكومي، والتمويل الأهلي، والتمويل الذاتي وتعتبر أهم صور التمويل الذاتي هي التسويق الرياضي والاستثمار الرياضي، ويعتبر التسويق الرياضي هو المفتاح لتحقيق أهداف المؤسسة

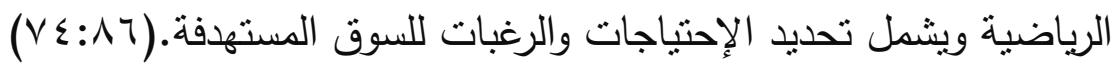
ولقد حظي التمويـل الذاتي بالهيئات الرياضـية بقبول كبيـر بين مديري وأعضـاء مجالس إدارة الهيئات وأهدافها المسئولين عن الرياضـة بالجهات المعنية وان كان ذلك بلك على المستوى النظري، ولم يتم بعد على الصعيد العملي ، وحيث أن البيئة المعاصرة التي تتسم بالتعقيد وسرعة الحركة وتزايد المنافسة ، تؤكد على حتمية وضع خطة لزيادة

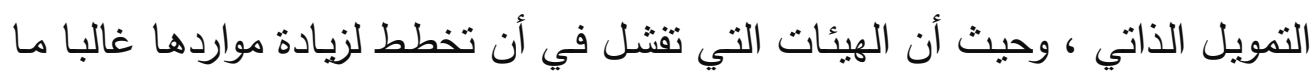

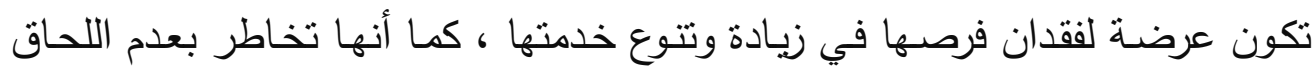
بـالتطور السـريع في الرياضــة والمتطلبـات والاحتياجـات المتغيـرة للجمـاهير ، وتواجـه 
بتطورات غير متوقعة ، وقد يكون الثمن الذي تدفعه هذه الهيئات لعدم التخطبط لإدارة

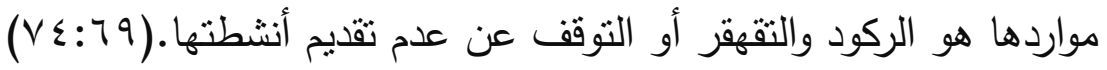
والتمويل الرياضى من أولويات الدراسات الإقتصادية والمالية والمصرفية والإدارية وغيرها من التخصصات التي تهتم بالتطورات الهيكلية التي شهدتها المجتمعات المنقدمة، وينصب اهتمام العائد الأقتصادى الرياضة المصرية خارج الاهتمامات

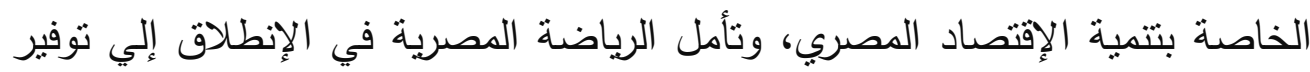

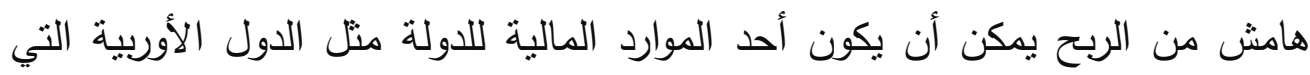

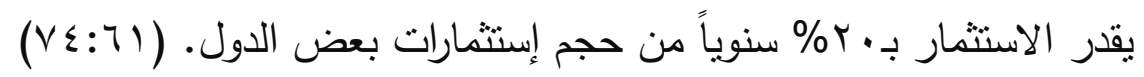
كما أن أهم طرق التمويل الرباضى في المجال الرياضي تتمثل في ضرورة إستثمار المنشآت الرياضية وتأجير الصالات وحمامات السباحة والمحلات وغيرها من صن المشاريع التي تدر عائداً مادياً يدخل ضمن إيرادات ذاتيه، وإنشاء شركات تجارية باسم المؤسسة الرياضية صاحبة المنفعة، ومحاولة التوصل لخصخصة الأنشطة الرياضية

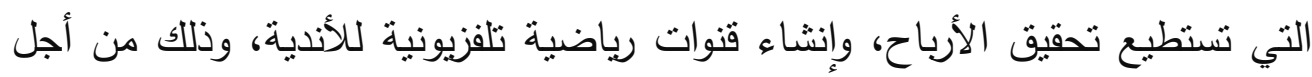
توفير الموارد المالية اللازمة للإزتقاء بمستوى المؤسسات الرياضية، وبيع حقوق النقل والبث الإذاعي والتلفزيوني، ورعاية اللاعبين المحترفين والتعامل معهم بمفهوم استثاري

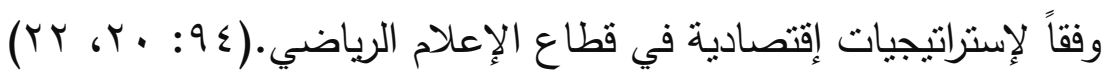
ومما لا شك فيه أن العلاقة التكاملية بين الأنشطة الرياضية والتمويل قد أدى إلى احتلال الرياضة مكانة رفيعة في الحياة الاجتماعية ولا تقل أهمية عن تلك التي تتالها علاقة الرياضة بالسياسة ولان نظام الرياضة يقوم على دعائم تمويلية تتمنل في

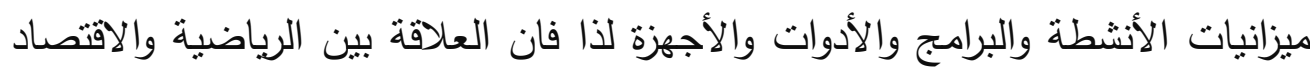
يتصل باعتمادها علية لتمويل مختلف أوجه النشاط بها كما بتصل برعاية المصالح التجارية والاستهلاكية للرياضة كمصدر للربح ووسيلة دعاية ناجحة قريبة ومحبية للمستهكين. ( 
ومن خلال المقابلات الثخصية التي أجراها الباحث مع عدد من العاملين بالمنشأت الرياضية بأسوان ، لاحظ أن مراكز الثباب بأسوان تواجه معوقات مالية كبيرة من حيث الثيث

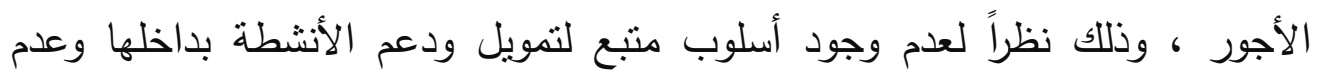
اللجوء إلى المصادر التمويلية الحديثة، وأنه لا توجد أموال كافية لتوفير الاحتياجات المالية المناسبة اللازمة للصرف على الخدمات التي تقلم بتلك مراكز الثباب للمستفيدين ، كما أن هناك عدم وعى من قبل إدارة المنشأت الرياضية بأسوان بأهمية

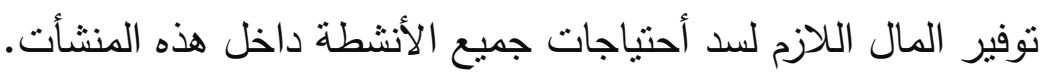
وذلك ما أشارت إليه نتائج العديد من الدراسات السابقة في مجال تمويل الرياضة مثل

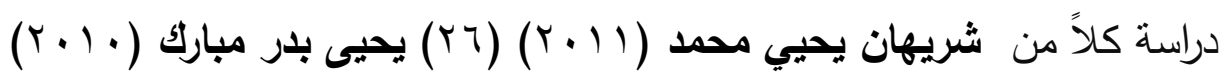

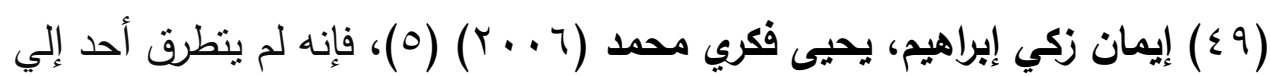
دراسة التمويل بالمنشأت الرياضية بصفة خاصة ، وعدم وجود أسلوب مناسب متبع للصرف على تلك الأوجه من الأنشطة ، وعدم الاعتماد على الأساليب الحديثة للتمويل أوضرورة وضع الخطط التمويلية المناسبة. مما دفع الباحث إلي إجراء هذه الدراسة كمحاولة منه لوضع خطة مقترحة لتحسين مصادر التمويل بالمنشأت الرياضية بمحافظات جنوب الصعيد. ثالثاً: أهمية البحث والحاجة إليه: الأهمية النظرية: النَا: المعه

- تكمن أهمية البحث النظرية في أنه لم تتعرض أي من المراجع أو البحوث أو الرسائل العلمية أو أي جهة متخصصة إلي محاولة دراسـة أساليب التمويل في المنشأت الرياضية بمحافظات جنوب الصعيد. - التعرف علي أنسب الطرق لتحسين أساليب التمويل في المنشأت الرياضية بمحافظات جنوب الصعيد. 
- إلقاء الضوء من الناحية النظرية على أساليب التمويل بالمنشأت الرياضية لأستفادة الباحثين منها.

- - وضع خطة مقترحة لتحسين أساليب التمويل المتبعة بالمنشأت الرياضية بصفة خاصة.

- الأستفادة من نتائج هذه الدراسة فى توجيه أنظار المسئولين فى إعداد الخطط التمويلية المناسبة التى تؤدى إلى تخفيف العبء المالي علي الموازنة العامة

$$
\text { لابعاً: هدف البحث: }
$$

يهدف البحث إلى وضع خطة مقترحة لتحسين مصادر التمويل في المنشأت الرياضية بمحافظات جنوب الصعيد. خامساً: تساوءلات البحث:

ا ـ ما أساليب التمويل الموجودة في المنشأت الرياضية بمحافظات جنوب الصعيد

$$
\varphi
$$

سادساً: بعض المصطلحات الواردة في البحث:

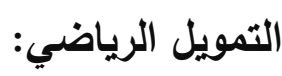

هو توفير الأموال اللازمة للمنظمة من المصادر المختلفة بتكلفة معقوله مـع استخدام

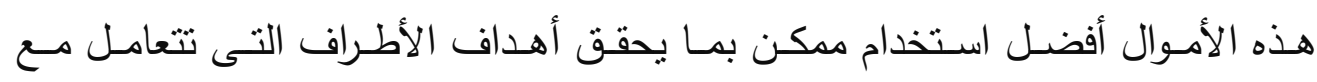

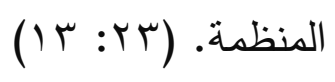




\section{التمويل الحكومي:}

هـو كل الإعانـات الماليـة والعينيـة التـى تـدعم بهـا المنظمـة الرياضـية عـن طريـق المنظمـات الحكوميـة التى تمتلكها الدولـة وخاصـة المجلس القومي للثـباب والرياضــة

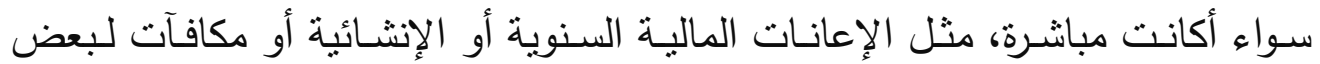

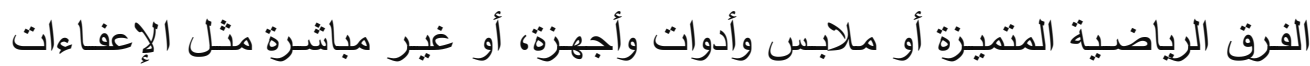
والتخفيضات المقررة للمنظمة الرياضية. (9 : 0 ( )

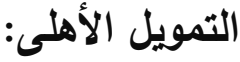

يتضمن التمويل الأهلى كلا من التبرعات المالية والعينية التى تأتي للمنظمة الرياضية عن طريق الأفراد أو الثركات او المؤسسات من داخل مصر أو خارجها بعد موافقة

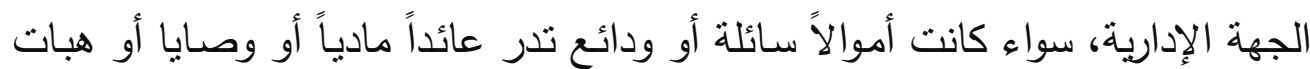

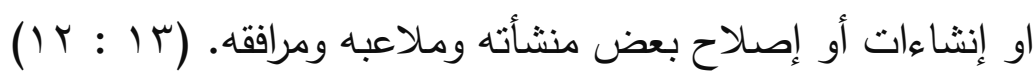

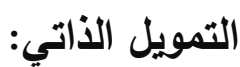

يتضمن التمويل الذاتى كل الإيرادات التى تحققها المنظمة الرياضية عن طريق استثمار

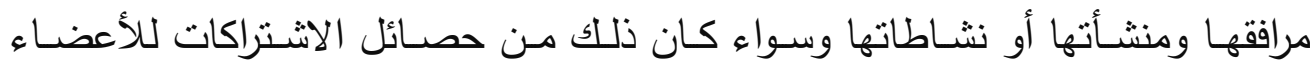
العـاملين أو أسـرهم او رسـوم العضـوية او بيـع تـذاكر دخـول الزائـرين إليهـا ودخـل

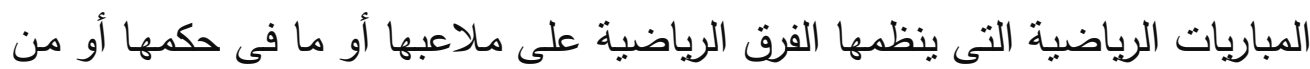
دخل الحفلات أو عائدات الودائع المالية التى تمنلكها.(1 : 9 (

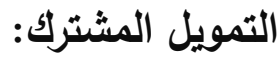

هو ذللك اللون من التمويل الذى يجمع بين الإيرادات الذاتية للهيئة الرياضية والتبرعات

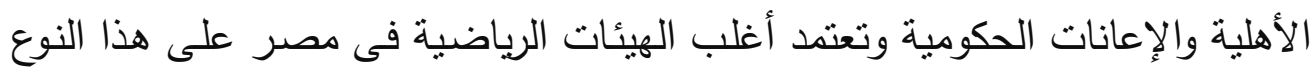

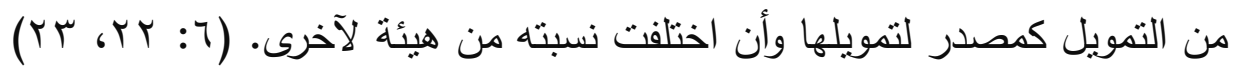

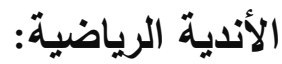


تعرف الأنديـة الرياضية بأنها منظمـات رياضية وترويحيـة، تهدف إلى الإسـهام بـدور

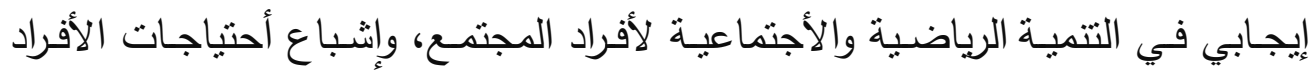

$$
\begin{aligned}
& \text { ورغباتهم فيما يتصل بالرياضة.(r) } \\
& \text { الاراسات السابقة: - }
\end{aligned}
$$

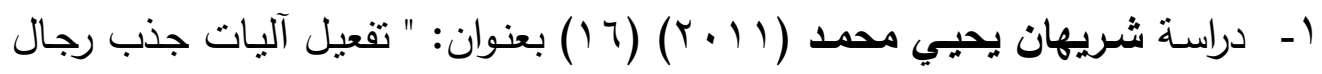
الأعمال للاستثمار في المجال الرياضي "، واستهدفت الدراسـة التعرف علي آليات ووسائل جذب رجال الأعمال للاستثمار في المجال الرياضي، واستخدمت الباحثة المنهج الوصفي للائمتهـه بطبيعـة الدراسـة وقامت بتطبيق البحث علي عبنـة من المستثرين ورجال الأعمال الذين يسوقون منتجاتهم من خلال الرياضة في (9) أندية بمحافظات مختلفة، وكانت أهم النتائج أن من أكثر المشروعات التي تحقق ربح ومكسب مادي من وجهة نظر المستشرين ورجال الأعمال هي مشروعات الإنتــاج والتوزيــع كتصـنيع الملابـس والأدوات الرياضــية، ومشـروعات الإنثـــاء والتعمير وإنشاء الأنديـة والصـالات متعددة الأعراض، كما استتنجت الدراسـة عدم وجـود أسـاليب وقرارات تجذب المستثمرين، وأيضـا لا توجد إدارات مسئولية عن الاسـتثمار والتسـويق والتمويـل في معظم المؤسسـات الرياضـية، وكذلك صسوبة الإجراءات الإدارية الخاصة بالاستثمار في المجال الرياضي.

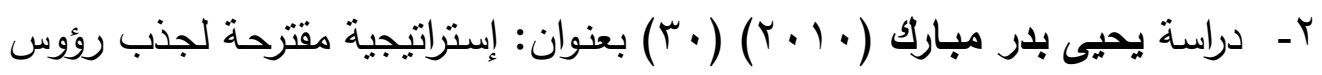
الأموال للاستتمار في الأنديـة الرياضية الكويتية واستهدفت الدراسـة التعرف على الوضـع الـراهن للاسـتمار بالأنديـة الرياضـية لدولــة الكويـت ووضـع إسـتراتيجية مقترحسة لجذب رؤوس الأمـوال للاسـتثمار في الأنديـة، واستخدم الباحث المـنهج الوصفي متبعا الأسلوب المسحي وكانت عينة الدراسـة اشتملت على (• (Y) من 
أعضـاء مجـالس إدارات الأنديـة ومجلس الأمــة الكـويتي وكانـت أهـم النتـائج أن المنشـآت الرياضية بدولة الكويت لا نستثمر الجانب المـالي والبشري للدي البيئة المحيطة ولا تشجع رجال الأعمال والمستتمرين على الاستثمار ولا توجد تسهيلات إلى رجال الأعمال للاستثمار في المجال الرياضي ولا يوجد نص تشريعي يثجع على لاستثمار بالأندية الكويتية.

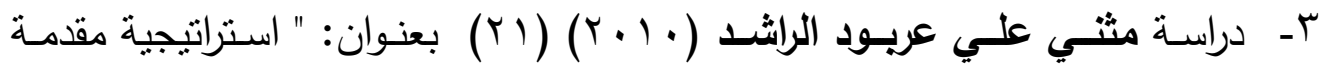
لتطوير التسويق الرياضي بدولة الكويت " واستهداف الدراسة التعرف علي تصميم اسـتراتيجية الرياضــة ولـه الكويـت واستخدام الباحـث المـنهج الوصـفي بالأسـوب المسحي واستلمت عينة الدراسة علي 199 فرد من أعضاء مجالس إدارات الأندية

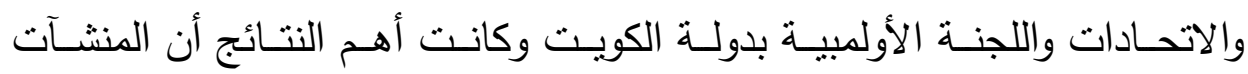
الرياضية بدولة الكويت لا نستثمر الجانب المالي والبشري لدي البيئة المحبطة ولا يتم تسويق المنشآت الرياضية داخل الأندية وأن هناك الكثير من المعوقات التي تحول دون استثمار وتشويق الأندية بدولة الكويت. ع - دراسـة أحمد فتحي الأفندي (9 . . ب) (r) بعنوان: " الإدارة الاستراتيجية للتسويق بالاتحـادات الرياضـية المصـرية - دراسـة استشـرافية، واستتهدفت الدراسـة تصـيم نمـوذج لـلإدارة الاسـتراتيجية للتسـويق بالاتحـادات الرياضـية المصـرية فـى ضـوء استشـراف مستقبل صـناعه الرياضـة فى مصـر بشكل عـام والتسـويق بالاتحـادات الرياضية المصرية بشكل خـاص، واسـتخدم الباحث منهج الدراسـات المستقبلية، وبلغت عينة الدراسة (ع ( ) فرد من المهتمين بالرياضة المصرية، وعدد ب ا خبير مـن متخـذى القـرارات بالاتحـادات الرياضـية وخلصـت نتـائج الدراسـة إلـى رسـم 


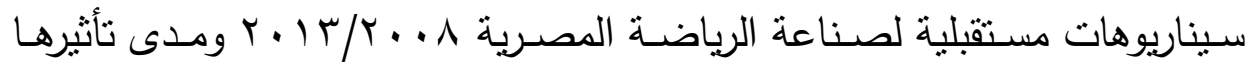
بالبيئة السياسية والاقتصادية والاجتماعية والثقافية والقانونية والتشريعية.

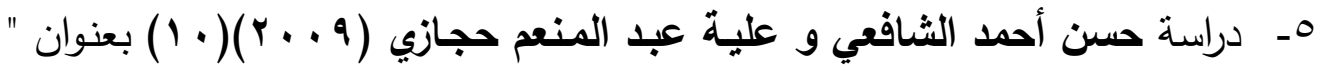

إسـتراتيجية للتسـويق الرياضــي والاسـتثمار بالمؤسسـات الرياضــية المختلفـة "، واسـتهدفت الدراسـة وضـع إسـتراتيجية للتسـويق الرياضـي والاسـتثمار بالمؤسسـات الرياضية في ضوء التحولات الاقتصـادية العالميـة المعاصـرة، واستخدام الباحثات المـنهج الوصـفي بالأسـلوب المسـي والتحليـل ألارتبـاطي المقارن، وكانت عينـة البحث الذي تم اختيارها بالطريقة العشوائية وهي هو؟ فرد من الإدارة العليا، ــ مسـتثر و رجـل أعمـال مـن كثـوف السـجلات التجاريـة، وكانـت أدوات جميـع البيانات هي تحليل اللوائح والقوانين المنظمة للمؤسسات الرياضية المختلفة وقانون

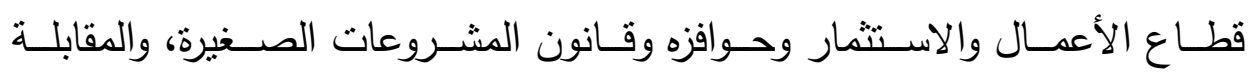
الثخصية، واستمارة الاستبيان، وكانت أهم النتائج اقتراح مشروع متكامل لعملية التسويق الرياضي والاستثمار بالمؤسسات الرياضية المختلفة.

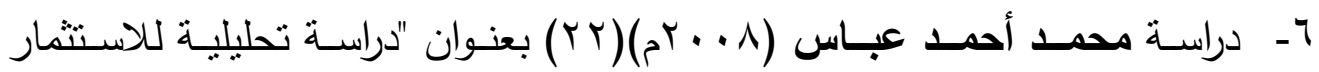
بالأنديـة الرياضـية الخاصـة في ج·م·ع"، وقـد هـدفت هـذه الدراسـة إلى تحليـل الاسـتثمار بالأنديـة الرياضـية الخاصـة بمصـر، ووضـع تصـور حـول الاسـتثمار بالأنديـة الرياضـية الخاصـة بمصـر، واسـتخدم الباحث المـنهج الوصـفي بأسـوب الدراسـات المسـية، واشـتملت عينـة البحث على عدد مـن الخبراء في المجـال الرياضــي والمجـال الاسـتثماري، والمسئولين بالأنديـة الخاصـة، وبعض قيـادات المجلس القومي للرياضـة، وخبراء أكاديميين، واستخدم الباحث المقابلة الثخصية 
وتحليل الوثائق كأدوات لجمع البيانـات، ومن أهم نتائج تلك الدراسـة: أن الدولـة لـديها رؤيسة مسـتقبلية لنتـيع الاسـتثمار الرياضـي وتعاملها إيجـابي مـع قضـية الاستثمار في مجال الأندية الخاصـة، يتطلب نتجيع الاستثمار في مجال الأندية الرياضية وضع تشريعات وقوانين ولوائح جديدة.

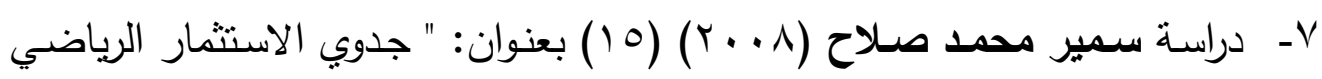
في مجال السياحة "، واستهدفت الدراسة التعرف علي الفروق بين استجابات أفراد عينة البحث المختارة بأندية القطاع الخاص والأهلي والحكومي في محاور جدوي الاسـتثمار الرياضـي في مجـال السـياحة وقد اسـتخدم الباحث المنهج الوصـفي

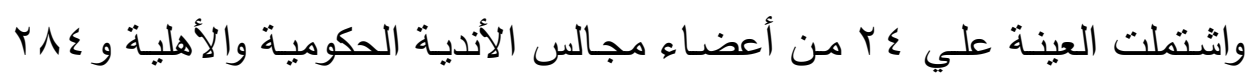
مـن الأجهزة الإداريـة والفنبـة ومديريـة النشـاط، و^م فرد مـن المستثرين ورجـال الأعمال، و 1 • ا من أعضاء الأندية الرياضية، وكانت أهم نتائج الدراسة أن إدارة النـادي تعجز عن مواجهـة المصـروفات المتزايـدة لرياضــة السباحة، وأن أثـكال ومجـالات الاســتثمار محـدودة بالنـادي، وصـعوبة تشـجيل الثــركات الخاصــة بالاستثمار الرياضي في البورصة.

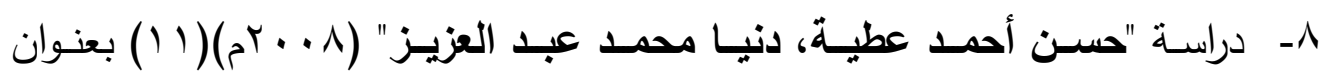
"التأجير التمويلي كمدر استشمار الرياضي في المؤسسات الرياضية"، وهدفت إلى التعرف على متطلبات تطبيق التأجير التمويلي كمصدر للإستثمار الرياضي

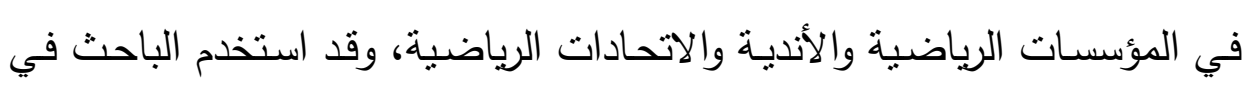
(171) من اعضاء مجالس إدارات الأندية الكبرى والاتحادات الرياضية والأندية، وتوصلت الدراسـة إلى نتائج أهمها: أهميـة التمويـل بصفة عامـة في المؤسسـات 
الرياضية لتوفير المال اللازم لها، اهميـة جير التمويلي في المؤسسات الرياضية حيث يعمل التأجير التمويلي على إستخدام آليات جديدة لتسهيل التمويل، التأجير التمويلي يحقق المرونة والاقتصاد والسيولة.

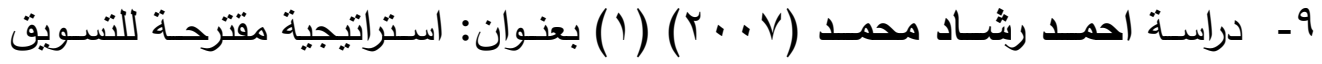
الرياضي لبطولات المبارزة، واستهدفت الدراسة تصميم استراتيجية تسويقية لبطولات المبارزة من خـلال تطبيق دائرة الفكر التسويقي الاستراتيجي داخل اتحاد السـلاح المصري استخدم الباحث المنهج الوصفي واشتمل عينة الدراسة على عينة قوامها V Vـرد لأعضــاء مجلـس الاتحساد والمـدير ومسـئول التسـويق وخبـراء التسـويق بجمهوريـة مصـر العربيـة، واسـتخلص الباحث عدم وجـود وحدة إداريـة للبحـوث التسويقية بالمؤسسات الرياضية تعمل على تصميم استراتيجيات تسويقية تتناسب مع مخرجات التحليلات الدورية للوضع القائم وتقويمه.

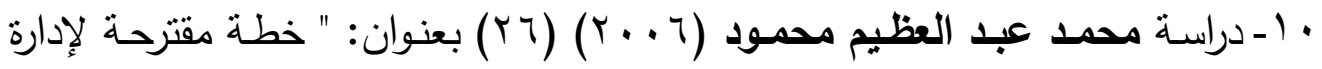
المؤسسات الرياضية فى ضوء الاهداف التسويقية" واستهدفت الدراسة التعرف على اساليب إدارة المؤسسات الرياضية (المركز الأولمبي بالمعادي - الإكاديمية العربية للنقل البحري بالإسكندرية - التعرف على نقاط القوة والضعف فى النظام الإداري بها، وتحليل للأساليب التسويقية التى يمكن تتفيذها فى ضوء الإمكانيات المتاحة، وتم اختبار عينـة البحث بالطريقة العشوائية من الاسـاتذة والخبراء والعاملين فى مجـال التربيـة الرياضـية، واسـتخدم الباحث في جمـع البيانـات اسـتمارة اسـتبيان وتوصلت نتائج الدراسـة إلى عدم وجود إدارة للتسويق داخل المؤسسات الرياضية 
وضرورة البحث عن مصادر لتمويل المؤسسات الرياضية وتقيم العمليات التسويقية داخل هذه المؤسسات.

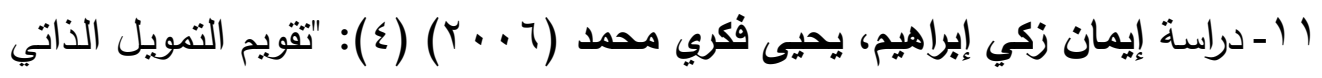
فى الاتحـادات الرياضـية الأولمبيـة المصـرية"، واستهدفت الدراسـة التعـرف علي لـي أهمية ومصادر التمويل الذاتي فى الاتحادات الرياضية المصرية وكذلك الضوابط القانونية ومعوقات النطبيق، استخدت الدراسة المنهج الوصفي واعتمدت فى جميع البيانات على الاستبيان وتحليل الوثائق والمقابلات الثخصية وكانت أهم النتائج ضـرورة الابتعـاد عن مخـاطر الاعتمـاد على مصـدر واحد للتمويـل وهـو الدعم الحكومى والعمل على زيادة فرص التمويل الذاتي للاتحادات الرياضية المصرية.

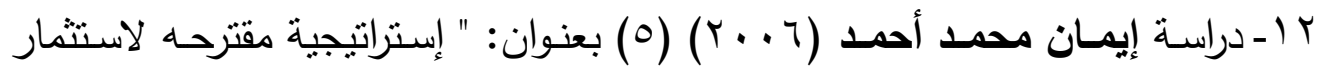
أنشطة الاتحاد المصـري لكرة اليد بجمهوريـة مصـر العربيـة، واستتهدفت الدراســة التعرف على العناصر التى يمكن من خلالها وضع استراتيجية لاستثمار الاتحاد المصري لكرة اليد، وأيضا التعرف على معوقات استثمار أنشطة الاتحاد المصري لكرة اليد، وثم اختبار عينة البحث بالطريقة العددية العشوائية من أعضاء مجلس إدارة الاتحـاد وأعضـاء اللجـان والمنـاطق والحكـام والمـدربين بـالإداريين وعـدهم (rq廿) فرد، واستخدمت الباحثة المنهج الوصفي لملائمته لطبيعة الدراسة، وكانت أهم النتائج التى توصلت إليها الدراسة أنه يمكن تحقيق أهداف الاتحاد بالإمكانيات الماديـة والبشـرية المتاحسة فى حالـة تسـويقها بطريقـة علميـة وأنـهـ لا يوجد خطـة استراتيجية لتسويق إمكانات الاتحاد المادية والبشرية وهناك معوقات تتمثل فى قلة 
الإمكانـات والتمويـل والتسـويق وهنـالك معوقـات قانونيـة وتشـريعية وإداريـة وفنيـة ومعوقات فى الوعي بالاستثمار الرياضي وفى الوعي بالسياسة الرياضية.

ب ا ـ دراسـة محمــ رجـب احمــ (T . . Y)(Y0) بدراسـة عنوانها "الخطـة الإسـتراتيجية لتسويق البطولات والمباريات الرياضية" بهدف التعرف على واقع عملية التخطيط الإستراتيجي لتسويق البطولات والمباريات الرياضية بالأنديـة الرياضية، واستخدم الباحث المنهج الوصفي (الدراسات المسحية والتحليلية) وكانت أهم النتائج التوصل إلـى تصـور لمـا ينبغـي أن تكـون عليـه الخطـة الاسـتراتيجية لتسـويق البطـولات والمباريات الرياضية من خلال تحليل الموقف التسويقي للنادي الرياضي، التعرف على السـوق المسـتهدف، تحديد أهداف وإسـتراتيجيات التسـويق، تصـيم المـزيج التسويقي المناسب للبطولات والمباريات الرياضية، وضـع الموازنـة المالية للخطـة التسويقية.

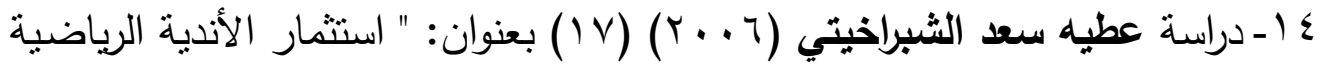
لنشـاط كرة القدم اقتصـاديا " واستهـفت الدراسـة التعرف علي الفوائد الاقتصـادية المتوقعة من استثمار نشاط رياضة كرة القدم المصرية اقتصاديا، واستخدم الباحث المنهج الوصفي وتم اختيار العينـة من مجموعة من الأفراد أندية الدوري الممتاز

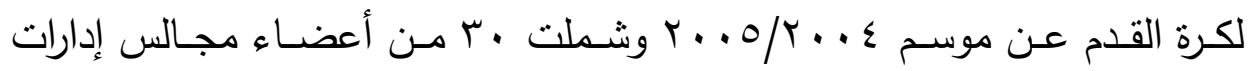
الأنديـة و • ب مـن اللاعبـين في الأنديـة، وكانـت أهــ نتـائج الدراسـة هـي تعقد التشريعات والقوانين بما لا يتيح الفرصة للاستثمار وعدم تسهيل الإجراءات الإدارية لاسـتخراج تصـاريح الاسـتثمار وضـف الاعتمـادات الماليـة الحكوميـة الموجهـة للأندية الرياضية. 
0 في الأنديـة الرياضـية"، وهدفت هـذه الدراسـة إلىى وضـع نمـوذج لإدارة التسـويق متضمن الأهداف والوظائف والأنشطة والهيكل التنظيمي والتي يمكن تطبيقها في الأنديـة الرياضية بهدف تسويق الخدمات التي تقدمها الأنديـة وذلك للعمل على تتميـة مواردهـا، واسـتخدم الباحث المـنهج الوصـفي بأسـلوب الدراسـات المسـية، واختار الباحث عينـة عمديـة قوامها ( •ـ) فرد من مديري الأنديـة ومديري إدارة التسـويق، ورؤسـاء مجـالس الإدارة بأنديـة الزمالك والأهلي والصـيد وهليوبـوليس، واستعان الباحث بتحليل الوثائق والمقابلة الثخصية كأدوات لجمع البيانات، وقد أشارت أهم نتائج نلك الدراسة إلى: أن تسويق النشاط الرياضي هو الوظيفة الأولى لإدارة التسويق مما يعكس محدودية النظر لوظائف إدارة التسويق وغموض مفهوم المزيج التسويقي وأهميـة الاستعانة بـأفراد متخصصين لإعداد الخطط التسويقيـة وأهمية القيام ببحوث التسويق للتعرف على المستهلك النهائي للخدمة من خـلال شركات متخصصة.

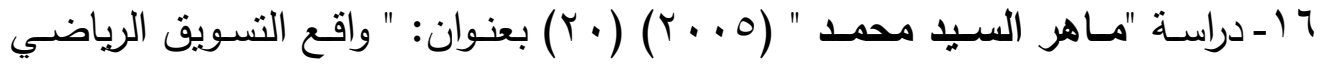
بالأنديـة الرياضية "، واستهدفت الدراسـة التعرف علي أهميـة التسويق من النواحي الاقتصادية والاجتماعية في المجال الرياضي، واستخدم الباحث المنهج الوصفي،

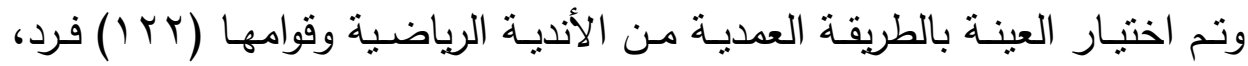
وكانـت أهم النتـائج التي توصـلت إلبهـا الدراسـة ضـعف القدرة التسـويقية لإدارة التسويق، عدم تشجيع رجال الأعمال علي التبرع ورعايـة الفرق الرياضية، وندرة المتخصصين المؤهلين في مجال التمويل والتسويق الرياضي. 


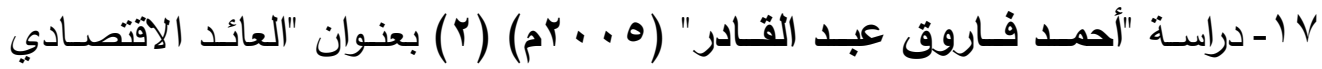
والسياسـي والاجتماعي للإنفاق الحكومي على الرياضـة القيمة" واستهدفت الدراسـة الكثـف عن العائد الاقتصـادي والسياسـي والاجتمـاعي للإنفـاق الحكومى على الرياضة القيمة، واستخدم الباحث المنهج الوصفي (الدراسات المسحية)، واشتملت العينة على الاتحادات الرياضية الأولمبية بجمهورية مصر العربية حيث بلغ عدد الاتحادات (Yr) اتحاد أولمبي، حيث بلـغ عدد العينة (Y Y (Y) فرد ممثلين لهذه الاتحادات، واستخدم الباحث استمارة الاستبيان والمقابلة الشخصية كأدوات لجمع البيانات، وكان من أهم النتائج إنخفاض مستوى الصرف على الاجهزة والأدوات في المنشآت الرياضية.

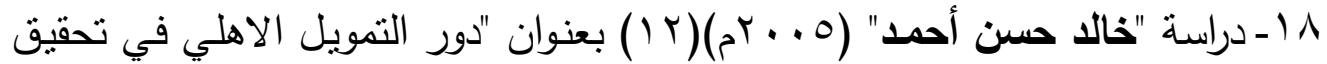
أهـداف النشـاط الرياضـي لبعض الانديـة الكبـرى في جمهوريـة مصـر العربيـة" واستهدفت الدراسة تحديد دور التمويل الأهلى في تحقيق أهداف النشاط الرياضي لبعض الأنديـة الكبرى في جمهوريـة مصـر العربيـة، واسـتخدم الباحـث المـنهج الوصفي المسحي، واشتملت العينة على مجموعة من الأندية الكبرى وصل عددها إلى (• (1) أندية تم اختيارهم بالطريقة العدية وتتكون من (بعض أمناء الصندوق بالأندية الكبرى، مديري ومشرفي النشاط بالأندية الكبرى)، بلغ إجمالي حجم العينة الكلية على (7 1 (1) فردا، وكانت أهم النتائج عدم وجود الدعم المـالي المناسب لتحقيق أهداف النشاط الرياضي، عدم الاهتمام بزيادة قاعدة الممارسين للنشاط الرياضـي، إن مصدر التمويـل الأهلي لـه أهميـة كبيرة في الوقت الراهن بالنسبة للأنديـة الكبرى وذلك نتيجة زيادة النفقات الخاصـة بالنشـاط الرياضـي والإجراءات 
الروتينية المعقدة التي تتم عند قيام إحدى الجهات الأهلية بعملية تمويل للنشاط الرياضي، عدد الملاعب لا يتتاسب وأنواع النشاط الرياضي الممارس.

$$
\text { - منهج البحث : }
$$

أستخدم الباحث المنهج الوصفي (الدراسات المسحية) لملائكته لطبيعة الدراسة.

$$
\text { - مجتمع البحث : - }
$$

يتكون مجتمع البحث وفقاً لطبيعة وأهداف البحث من العاملين في المنشأت

$$
\text { - الرياضية بمحافظات جنوب الصعيد. }
$$

\begin{tabular}{|c|c|c|c|c|}
\hline المجموع & العاملين بإدارة النشاط & مديرين تنفيذين & مجالس إدارات & توصيف العينة \\
\hline $1 \ldots$ & rvo & 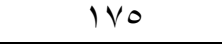 & 纟o. & المجتمع \\
\hline TrY & IYY & 0. & 10. & عدد العيذة \\
\hline
\end{tabular}

تم أختيار عينة البحث بالطريقة العشوائية من العاملين في المنشأت الرياضية

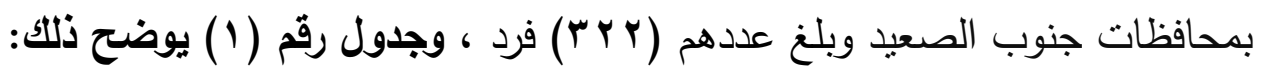

جدول (1)

لجمع البيانات والمعلومات الخاصة بالدراسة الحالية أستخدم الباحث ما يلي :

1. المقابلة الشخصية .

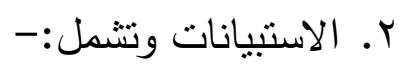

الرياضية في المنشأت الرياضية بمحافظات جنوب الصعيد. 
استمارة الاستبيان: أساليب التمويل المتبعة في المنثأت الرياضية في المنثأت الرياضية بمحافظات جنوب الصعيد:

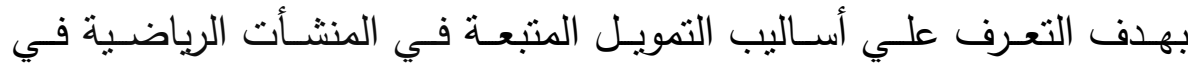

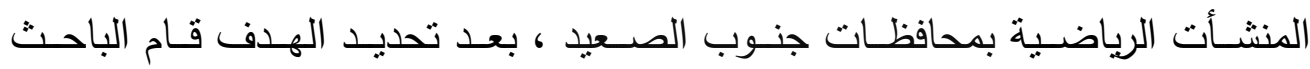

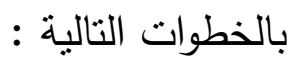
1- تحديد المحاور الرئيسية للاستبيان:

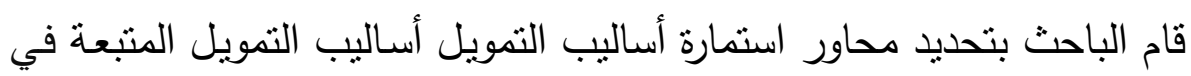

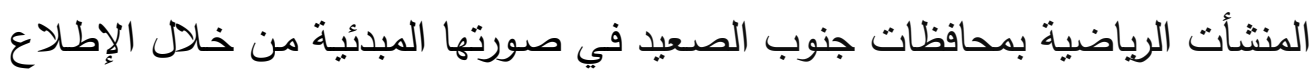

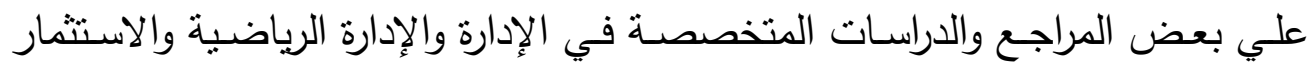
والتمويل الرياضي ب r - عرض المحاور علي الخبراء:

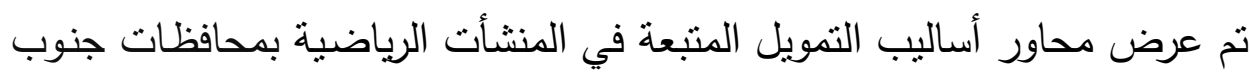

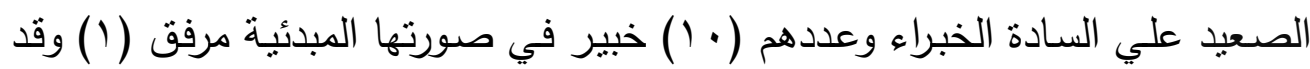
لجأ الباحث إلي السادة الخبراء للتعرف علي : لإداء - - مدي مناسبة وكفاية المحاور الرئيسية. - تعديل أو حذف ما يراه الخبير من محاور رئيسية. وبعد عرض الاستمارة علي السادة الخبراء قام الباحث بحساب النساء النسبة المئوية

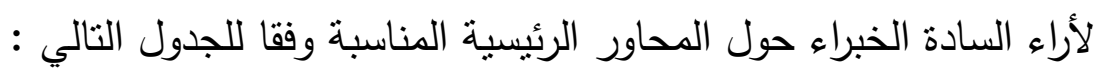




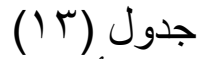

الدرجة المقدرة والنسبة المئوية لأمر اء السادة الخبر اء وفي محاور

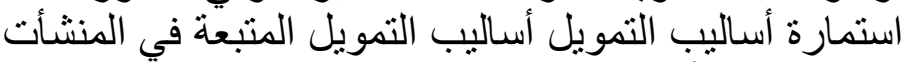

$$
\text { الرياضية بأسوان }
$$

\begin{tabular}{|c|c|c|c|}
\hline المئوية & 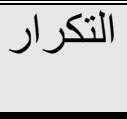 & 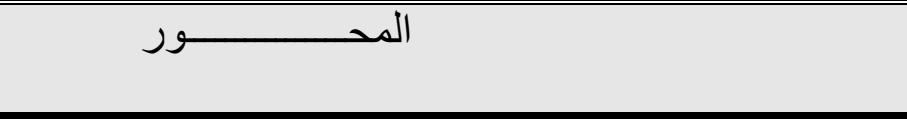 & r \\
\hline$\% 9$. & 9 & دور المنشات الرياضية والثبابية كأحد مصادر التمويل المتبعة. & 1 \\
\hline$\% \wedge$. & $\wedge$ & دور التمويل الحكومي والأهلي كأحد مصادر التمويل المتبعة. & r \\
\hline$\% 7$. & 7 & دور الوعي في التسويق الرياضي · & r \\
\hline$\% 0$. & 0 & دور الجهات الإدارية والرقابية علي المنشأت الرياضية. & $\varepsilon$ \\
\hline$\%$ r & r & دور النواعي الفنية الخاصة بخبراء التمويل . & 0 \\
\hline$\% \varepsilon$. & $\varepsilon$ & دور الثركات الراعية والمدارس الرياضية . & 7 \\
\hline$\% 0$. & 0 & دور اللوائح المالية والقوانين الخاصة بالمنشأت الرياضية. & $V$ \\
\hline$\% 7$. & 7 & دور الاستثمار بالمنشأت الرياضية كأحد مصادر التمويل & $\Lambda$ \\
\hline
\end{tabular}

يتضـح من الجدول السـابق (r I أن النسبة المئويـة لأراء السـادة الخبراء حول

المحاور الرئيسية لاستمارة أساليب التمويل في الهيئات الرياضية والثبابية قد تراوحت التبه

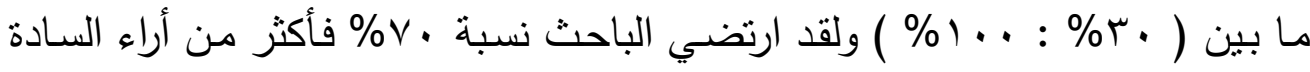
الخبراء ، وعلي هذا قد تم التوصل إلي عدد r محور لاستمارة أساليب التمويل المتبعة

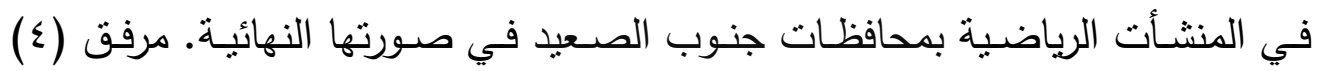
وهما:

ا - دور المنشآت الرياضية والثبابية كأحد مصادر التمويل المتبعة. r- دور التمويل الحكومي والأهلي كأحد مصادر التمويل المتبعة.

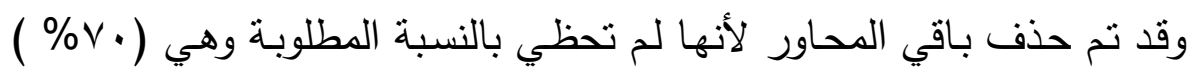
فأكثر من أراء السادة الخبراء. 


\section{r- إعداد عبارات الاستبيان :}

في ضوء نتائج أراء الخبراء حول المحاور المقترحة قام الباحث بدراسـة كل محور علي حدة وذلك لتحديد العبارات الخاصـة بكل محور مسترشدا ببعض المراجع

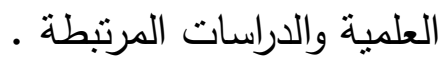

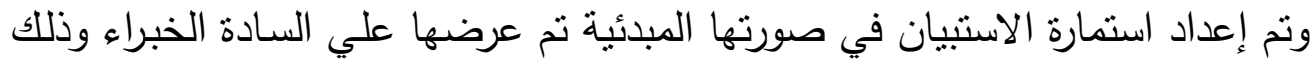

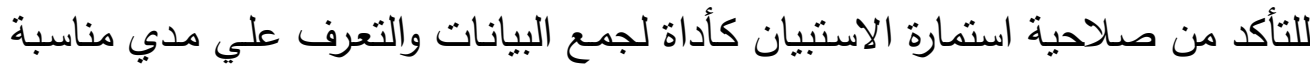

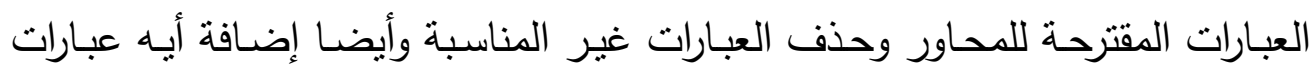
أخري مقترحة تكون غير مدرجة بالاستمارة والجدول ( ع () يوضح النسبة المئوية لأراء

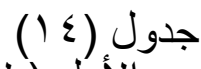

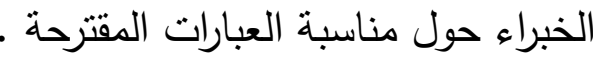
معاملات الارتباط بين عبار ات المحور الاول ( لاستمارة أساليب التمويل المتبعة في وني

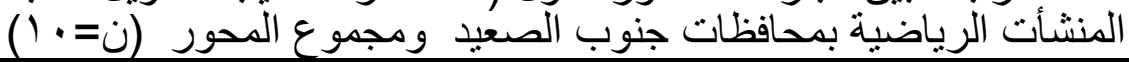

\begin{tabular}{|c|c|c|c|}
\hline المئوية & التكر ا & 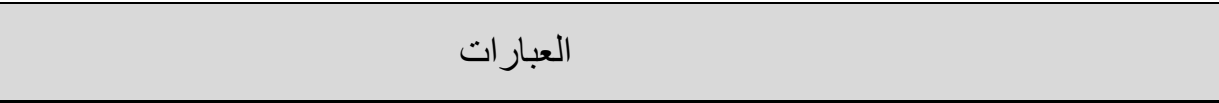 & 5 \\
\hline & & المحور الأول: دور المنشآت الرياضية كأحد مصادر التمويل: & \\
\hline$\% 1 \ldots$ & 1. & مراكز الثباب تهدف إلى أقامة البطولات المحلية والدولية. & 1 \\
\hline$\% q$. & 9 & مراكز الثباب تعمل على الإستشمار المالى والبشرى لموارد البيئة المحيطة . & r \\
\hline$\% 1 \ldots$ & 1. & الأماكن الثاغرة المنشأت الرياضية لا تستغل لزيادة التمويل والتسويق والاستثمار . & r \\
\hline$\% \wedge$. & $\Lambda$ & المنشأت الرياضية تنتخل العائد المادى لأعمال الصيانة والتجديدات. & $\varepsilon$ \\
\hline$\% 1 \ldots$ & 1. & لا يوجد المنشأت الرياضية نظام يعمل على جذب الأفراد والمستشرين. & 0 \\
\hline$\% \vee$. & V & يوجد بالمنشأت الرياضية إداريون متخصصون فى التسويق. & 7 \\
\hline$\% 1 \ldots$ & 1. & أعداد الأخصائيين الرياضيين لايتتاسب مع أعداد المتدربين داخل المنشأت الرياضبة. & V \\
\hline$\% \wedge$. & $\Lambda$ & يتم استغلال الملاعب داخل المنشأت الرباضية لأكثر من نشاط رياضي. & $\wedge$ \\
\hline$\% 1 \ldots$ & 1. & السعة الاستيعابية بالمنشأت الرياضية محددة لاستغلالها الجيد أثناء عمل الأنشطة والمباريات. & 9 \\
\hline$\% \vee$. & V & الملاعب المفتوحة المنشأت الرياضية لا يتم تسويقها لزيادة التمويل • & 1. \\
\hline$\% 1 \ldots$ & 1. & يفضل في اختيار مديري المنشأت الرياضية أثناص لديهم روية في زيادة التمويل الذاتي. & 11 \\
\hline \multirow[t]{2}{*}{$\% \varepsilon$. } & $\varepsilon$ & يحصل الإداريين علي مكافأت رمزية مقابل أعمالهم • & IT \\
\hline & & المحور الثاني : دور التمويل الحكومي والأهلي كأحد مصادر التمويل: & \\
\hline
\end{tabular}




\begin{tabular}{|c|c|c|c|}
\hline$\% 1 \ldots$ & 1. & لا يوجد نص تشريعى بمراكز الثباب لزيادة قيمة التمويل الحكومى . & 1 \\
\hline$\% \wedge$. & $\wedge$ & لا توجد عدالة فى توزيع الدعم المالى بين المنشأت الرياضية على مستوى الجمهورية. & $r$ \\
\hline$\% 1 \ldots$ & 1. & يوجد أهتمام من القيادات العليا بوزارتي الثباب والرياضة بالمشاكل المالية المنشأت الرياضية. & $r$ \\
\hline$\% \wedge$. & $\wedge$ & يوجد تضخم بالجهاز الإداري بمراكز الثباب يعمل على أستتزاف التمويل الحكومى والأهلى. & $\varepsilon$ \\
\hline$\% 1 \ldots$ & 1. & القوانين الموجودة أو اللائحة التنظيمية لا تحدد قيمة التمويل المالى الحكومى المنشأت الرياضية. & 0 \\
\hline$\% 1 \ldots$ & 1. & نظراً لأتجاه الدولة لخصخصة الهيئات العامة يقل الدعم الحكومى عام بعد عام للمنشأت الرياضية. & 7 \\
\hline$\% q$. & 9 & يفضل فى أختيار مديرى المنشأت الرياضية أنثخاص لديهم رؤية فى زيادة التمويل الذاتى . & V \\
\hline$\% 1 \ldots$ & 1. & ضرورة الموازنة بين قيمة إيجار المنشأت الرياضية والظروف الأقتصادية لكل محافظة & $\wedge$ \\
\hline$\% \vee$. & $\checkmark$ & الدالية ـ المقدم من رجال الأعمال والمستثرين فى البيئة المحيطة بالمنشأت الرياضية لا يفى بالاحتياجات & \\
\hline
\end{tabular}

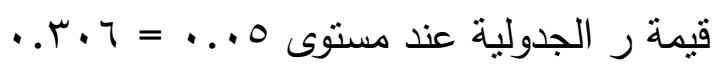

يتضح من الجدول (ع () أن النسبة المئوية لأراء السادة الخبراء حول مناسبة

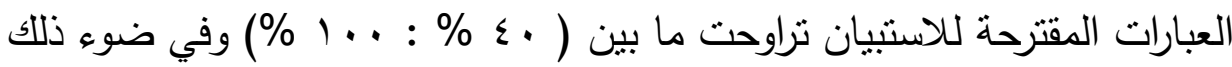
ارتضي الباحث نسبة • V \% فأكثر وتم استبعاد العبارات التي لم تحصل علي هذه النسبة بالإضافة إلي تعديل وصياغة بعض العبارات بناءا علي أراء السادة الخبراء

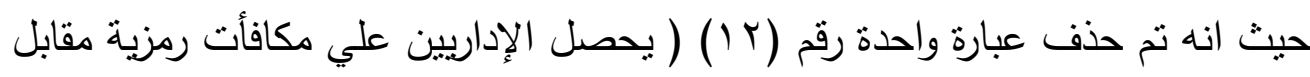
أعمالهم) من المحور الأول (دور المنشآت الرياضية كأحد مصادر التمويل في المنشأت الرياضية بمحافظات جنوب الصعيد). وجدول رقم (0) يوضـح عدد عبـارات الاستبيان الخـاص باستمارة أسـاليب التمويل المتبعة بالمنشأت الرياضية بأسوان قبل وبعد العرض علي الخبراء . 


\section{جدول (10) (10)}

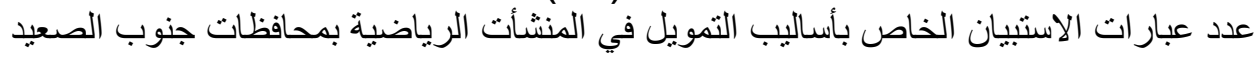

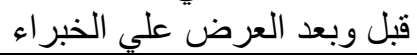

\begin{tabular}{|c|c|c|c|c|c|}
\hline عدد العبار ات بعد علي & إضـافة & حذف & 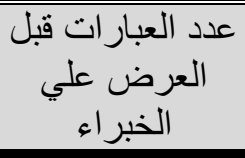 & المحــــــــــــاور & r \\
\hline 11 & - & 1 & Ir & بالمنشأت الرياضية. & 1 \\
\hline 9 & - & - & 9 & بالمنشأت الرياضية. الحكومي والأهلي كأحد مصسادر التمويل & r \\
\hline$r$. & - & 1 & r) & المجموع & \\
\hline
\end{tabular}

ع - الاراسة الاستطلاعية للاستبيان الثاني:

لاختبـار وضـوح عبـارات الاسـتبيان قـام الباحـث بـإجراء دراسـة اسـتطلاعية

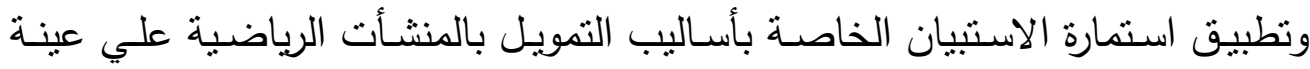

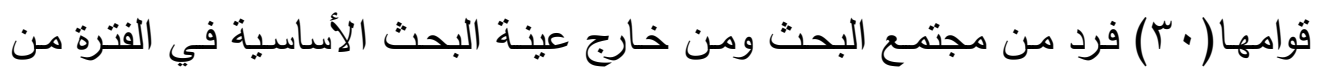

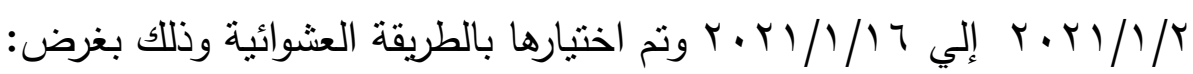
- التأكد من صحة صياغة العبارات مع تعديل العبارات الغامضة. - التعرف علي المشكلات التي يمكن أن تواجه الباحث أثثاء التطبيق. - إيجاد المعاملات العلمية للاستمارة ( الصدق ، والثبات). وقد أظهرت نتائج الدراسـة الاستطلاعية أن الاستبيان جاء مناسبا من حيث ونثات الصياغة واللغة المستخدمة ولم تظهر أي مشكلات أو تعليقات توحي بالغموض وعدم الانيان الفهم.

ه- المعاملات العلمية للاستمارة:

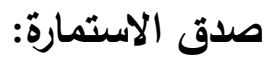


اسـتخدم الباحث صـدق الاتسـاق الداخلى لحسـاب معامـل الصـدق للاسـتبيان

وذلك بهدف التحقق من صدق استمارة الاستبيان، حيث تم تطبيق الاستبيان على البى

مجموعة قوامها ( • ب) فرد من مجتمع البحث ومن خارج عينة البحث الأساسية.

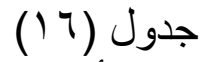

معاملات الارتباط بين عبار ات المحور الأول دور المنشآت الرياضية كأحد مصادر التمويل

في الهيئات الرياضية والثبابية : ومجموع المحور

(r.=ن)

\begin{tabular}{|c|c|c|c|c|}
\hline قليمة ر المحسة & الانحرا & الحستوسطي & العبــــــــــار ات & r \\
\hline..$\wedge 1$ & 1.77 & r.ı & مراكز الثباب تهدف إلى أقامة البطولات المحلية والدولية. & 1 \\
\hline.$\wedge r$ & $1.7 \pi$ & T.EV & مراكز الثباب تعمل على الإستثمار المالى والبشرى لموارد البيئة المحيطة. & r \\
\hline$\cdot \wedge$. & $1.0 r$ & r.s. & الأماكن الثاغرة بمراكز الثباب لا تستغل لزيادة التمويل والتسويق والاستثمار . & r \\
\hline.$A r$ & 1.71 & r.乏. & بالمنشأت الرياضية تستخل العائد المادى لأعمال الصيانة والتجديدات. & $\varepsilon$ \\
\hline . . & $1.7 \varepsilon$ & r.rv & لا يوجد بالمنشأت الرياضية نظام يعمل على جذب الأفراد والمستثرين. & 0 \\
\hline.$A r$ & 1.71 & r.s. & يوجد بالمنشأت الرياضية إداريون متخصصون فى التسويق. & 7 \\
\hline.$v_{0}$ & 1.00 & T.rV & أعداد الأخصائيين الرياضيين لا يتتاسب مـع أعداد المتدربين داخل بالمنشـأت & v \\
\hline.$V Y$ & 1.00 & $r . \leqslant V$ & يتم استغلال الملاعب داخل بالمنشأت الرياضية لأكثر من نشاط رياضي. & $\wedge$ \\
\hline. $.7 V$ & 1. & r.乏. & البطولات والمباريات الاسـتيعابية بالمنشـأت الرياضية محددة لاسـتخلالها الجيـد أثنـاء عمل & 9 \\
\hline $.7 V$ & $1.7 r$ & $r . . v$ & التمويل. المب المفتوحـة بالمنشـأت الرياضـية لا يـتم تسـويقها محليـاً وعالمبـاً لزبـادة & $1 \cdot$ \\
\hline.$v 1$ & 1.0. & r.7. & يفضل في اختيـار مديري بالمنشـأت الرياضية أشـخاص لديهم رويبة في زبـادة & 11 \\
\hline
\end{tabular}

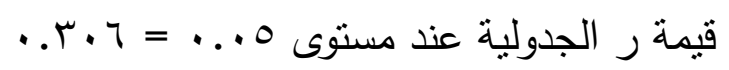


يتضـح من جدول رقم (7 1 ) أن معاملات الارتباط بين عبارات المحور الأول

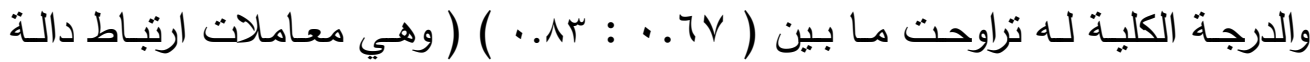

إحصائيا عند مستوي ( ه .. . ) مما يشير إلي الاتساق الداخلي للمحور.

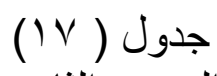

معاملات الارتباط بين عبار ات المحور الثاني: دور التمويل الحكومي و الأهلي

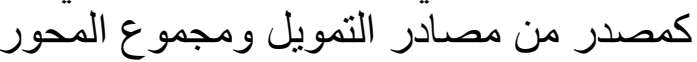

$$
\text { (ن) }
$$

\begin{tabular}{|c|c|c|c|c|}
\hline قامعسة ربة & الانحريار افي & المتوسطي الحسي & 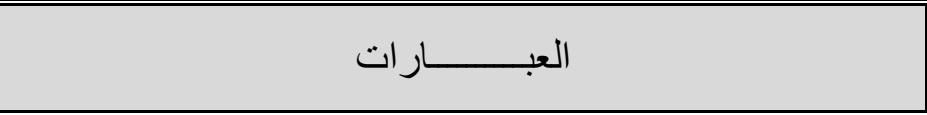 & 5 \\
\hline.$v q$ & $1.0 r$ & r.TV & 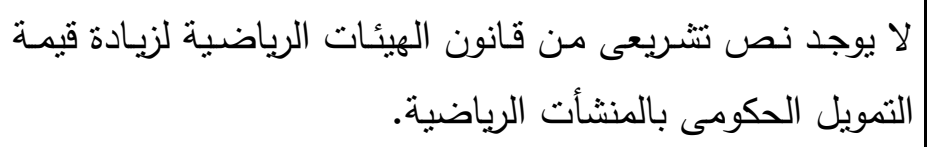 & 1 \\
\hline.$\wedge \varepsilon$ & $1.0 \mathrm{~V}$ & r.or & لا توجد عدالة فى توزيسع الدعم المـالى بين المنشـأت الرياضية & $r$ \\
\hline.$\wedge r$ & $1.7 \mathrm{~V}$ & זr.ץ & 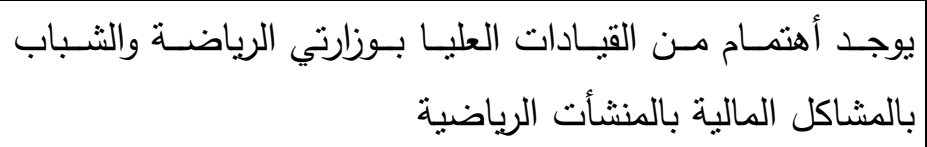 & r \\
\hline.$\wedge 1$ & $1.0 r$ & r.s. & 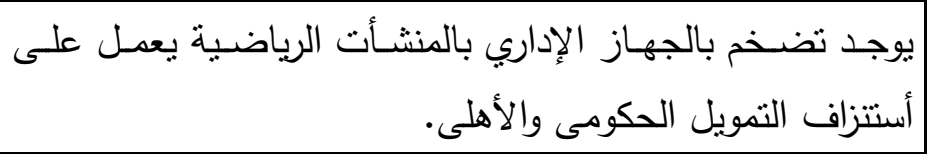 & $\varepsilon$ \\
\hline..$\wedge 1$ & 1.00 & $r . \Sigma V$ & القوانين الموجودة أو اللائحة التظظيمية تحدد قيمة التمويل المالى & 0 \\
\hline.$V \varepsilon$ & 1.00 & $r . \Sigma V$ & 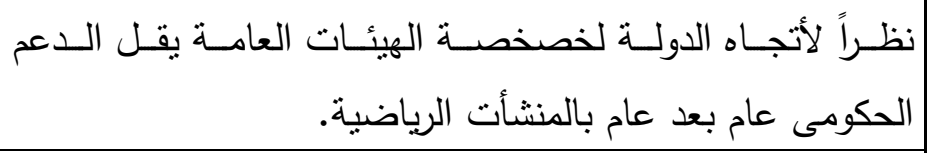 & 7 \\
\hline..$V r$ & 1.0 & r. & فيضل زيادة فى أختيار مديرى المنشأت الرياضية أثخاص لديهم رؤبة & v \\
\hline.$v_{1}$ & $1.0 r$ & •. & ضالأقتصرورة الموازنـة بين فيمـة إيجـار المنشـآت الرياضـية والظـروف & $\wedge$ \\
\hline$\cdot v^{\prime}$ & 1.0 & r. & لا لاعم المقدم من رجال الأعمال والمستثرين فى البيئة المحيطة & 9 \\
\hline
\end{tabular}




$$
\text { قيمة ر الجدولية عند مستوى } 0 \text {... }
$$

يتضح من جدول رقم (V V ) أن معاملات الارتباط بين عبارات المحور الثاني

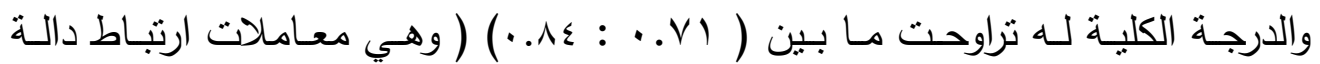

إحصائيا عند مستوي ( ه .. • ) مما يثير إلي الاتساق الداخلي للمحور .

- ثبات الاستبيان :

استخدم الباحث طريقة التطبيق واعادة التطبيق لحساب معامل الثبات لاستمارة

الاستبيان، وتم التطبيق على عدد (•r) فرد من مجتمـع البحث وخـارج عينـة البحث

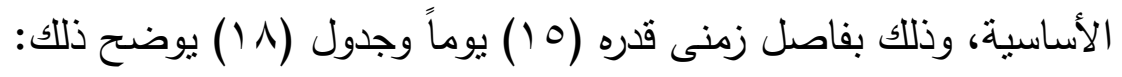

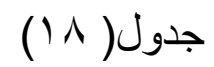

\begin{tabular}{|c|c|c|c|c|c|c|}
\hline \multirow{2}{*}{ قيمة ر } & \multicolumn{2}{|c|}{ التطبيق الثاني } & \multicolumn{2}{|c|}{ التطبيق الأول } & \multirow{2}{*}{ المحاور } & \multirow{2}{*}{5} \\
\hline & $\varepsilon$ & s & $\varepsilon$ & 5 & & \\
\hline. .99 & $1 \pi \ldots$ & ro.9r & IT.KV & r..人V & المحور الأول & 1 \\
\hline. .91 & 1.7. & $r \cdot . \varepsilon$. & $1 . . V r$ & MI. $\leqslant V$ & المحور الثاني & r \\
\hline. .99 & 人 & אז.דז & rT.AT & r. & الاستمارة ككل & $r$ \\
\hline
\end{tabular}

معامل الارتباط بين التطبيق الأول و التطبيق الثاني لمحاور

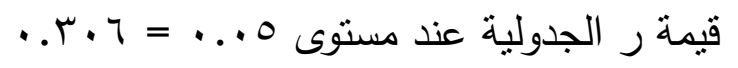

يتضـح من جدول رقم (1) أن معامل الارتباط بين التطبيق الأول والتطبيق

الثاني نراوحت ما بين ( 91 . . : 99 . . ) وهي معاملات ارتباط دالة إحصائيا عند

مستوي (0. . . ) مما يثير إلي ثبات الاستمارة .

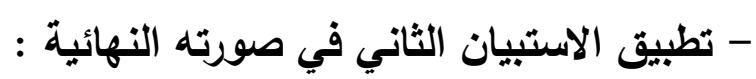


بعد إجراء المعاملات العلمية للاستبيان والتحقق من صدق العبارات وثباتها وذللك

باستبعاد العبـارات غير الصـادقة) إسـتقر الاستبيان في صـورته النهائيـة ( مرفق ه)

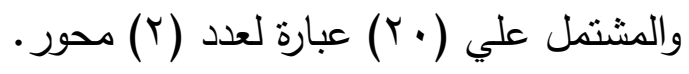

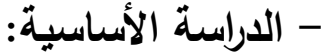

قام الباحث بتطبيق الاستبيان الثاني في صورته النهائية علي أفراد عينة البحث

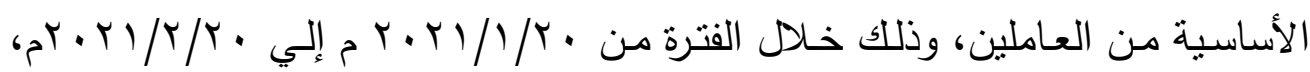

$$
\text { وفقا لميزان التقدير الثلاتي ( أوافق - إلي حد ما - لا أوافق). }
$$

الإجابة على التساؤل الثانى:-

استمارة أساليب التمويل فى الهيئات الرياضية و الثبابية:

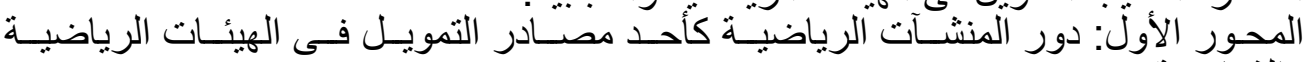

$$
\text { جدول (ON) }
$$

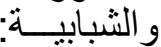

\begin{tabular}{|c|c|c|c|c|c|c|c|c|c|c|c|}
\hline & كارية & & أسوان & محاف & لأقصر & 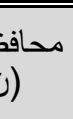 & 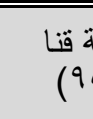 & & 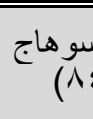 & محافز & ـار ات \\
\hline 5 & $\%$ & 5 & $\%$ & 5 & $\%$ & 5 & $\%$ & 5 & $\%$ & r & \\
\hline$V \varepsilon$ & ҮА... & $r \varepsilon$ & NT.VT & $r \varepsilon$. & ד... & YTI & $V \varepsilon . V \varepsilon$ & roo & VV.TY & TrT & البطولات المحلية والرياضية تهاف إلى أقامة \\
\hline$\wedge$. & $\wedge \ldots$ & $\varepsilon$. & $V I . V Y$ & $r \cdot \lambda$ & VT.AT & $r \cdot r$ & VT.Aq & rol & $v \cdot .90$ & Y9A & المالى والبشنشآت الرياضية تعمل على البيئة المحيطة. الإستثمار \\
\hline 71 & $v_{7} .$. & Tᄉ & 77.9. & $19 \leq$ & NT.rv & rrq & Vo.01 & roq & $V \leqslant . r q$ & rir & الأماكن الثاغتل لزيادة التمويل والتشويث المنشآت الرياضية لا لاستثمار \\
\hline$v$. & $\wedge \varepsilon \ldots$ & $\varepsilon r$ & ה & IVA & $V V . \leq 0$ & rוץ & VI.TV & qזr & VV.ls & TrE & الأعمال الصنشآت الرياضية تستغل العائد المادى \\
\hline 77 & $7 \varepsilon \ldots$ & rr & $\Upsilon \wedge . \Upsilon \wedge$ & 191 & AV.T & $r \leq 1$ & $\mathrm{VT. \wedge q}$ & rol & VT.TA & $r \cdot \varepsilon$ & على يوجد بالمنشآت الرياضية نظام يعمل \\
\hline V. & ҮА... & rs & Vo.IV & Y\A & V9.7s & 119 & VI.TV & qזr & ד.ד & r^. & متخصصين بالمنشآت الرياضية أفراد ( أداريين ) \\
\hline $7 \leq$ & $V V_{.} \ldots$ & די & 77.9. & $19 \varepsilon$ & $V Y . \leq 0$ & rir & Vr..o & $r \leq V$ & $v 1 . \leqslant r$ & r.. & أعداد الألثربين داخليين الرياضيين لا يتناسب مع المنشآت الرياضية. \\
\hline VY & $\wedge \varepsilon \ldots$ & $\varepsilon r$ & 77.9. & $19 \varepsilon$ & NT.rv & rrq & VT.TT & $r \leqslant 0$ & $V \leqslant . Y q$ & r & الرياضم استغلال الملاعث من داخل المنشات \\
\hline
\end{tabular}

الدرجة المقدرة والنسبة المئوية لاستجابات العينة في المحور الأول دور المنشآت الرياضية كأحد

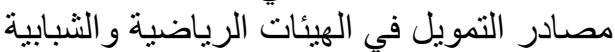




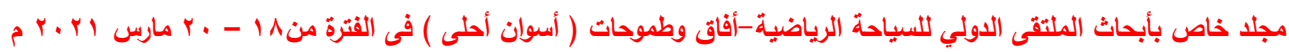

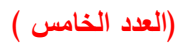

\begin{tabular}{|c|c|c|c|c|c|c|c|c|c|c|c|}
\hline$V_{T}$ & ז人... & $r \varepsilon$ & TE.Ar & 111 & V9.7 & r19 & vr..o & $r \leqslant v$ & VO. Y $\varepsilon$ & 417 & الجبا أثثاء الاستيعابية للمنشأة محلدة البطولات والمباريات. لاستغلالها \\
\hline v. & Vr... & r & TA. rA & 191 & A...4 & KrI & $V T . \leqslant V$ & $r \varepsilon q$ & $v \cdot .90$ & ra1 & 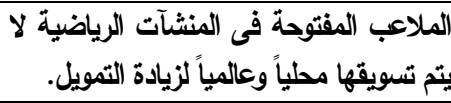 \\
\hline$\wedge$. & $\wedge \varepsilon \ldots$ & $\varepsilon r$ & Tr.Y & 194 & $10 . \leqslant 0$ & rTo & VY.YT & rTV & $V \leqslant . r q$ & TIY & فيضل في اختيار مليري المنشآت الرياضية \\
\hline$\vee q$. & $V \leqslant .00$ & $\leqslant 1$. & $79 . .4$ & Yr. & A..vr & $r \leqslant \leqslant r$ & VT.TV & $r \wedge \varepsilon q$ & VT.r. & THAT & مجموع المحور \\
\hline
\end{tabular}

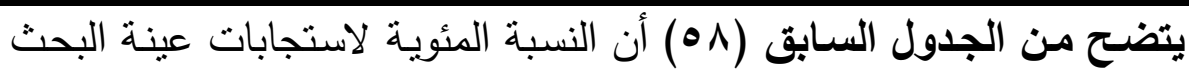

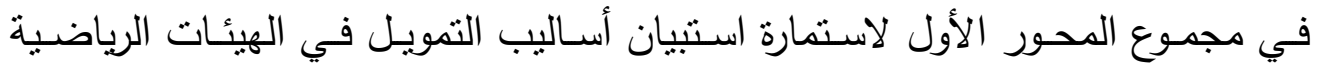

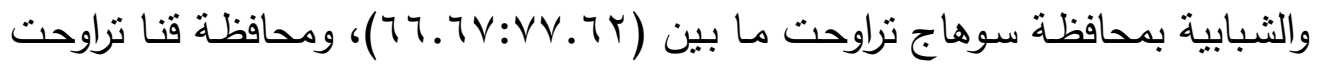

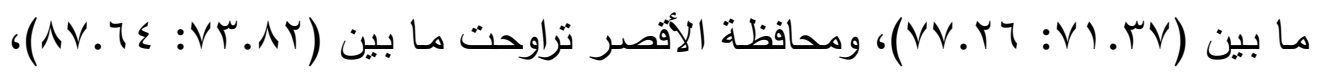

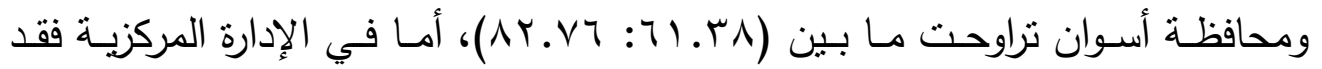

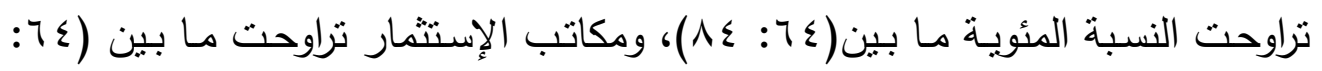

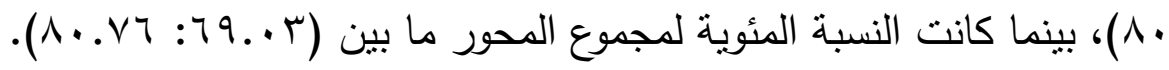

كما يتضح من نتائج الجدول رقم (O1) أن النسبة المئوية لإستجابات عينة

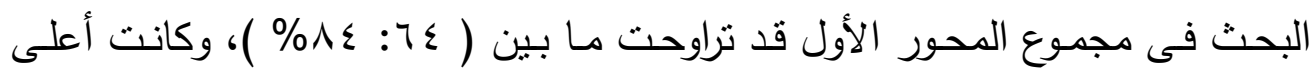

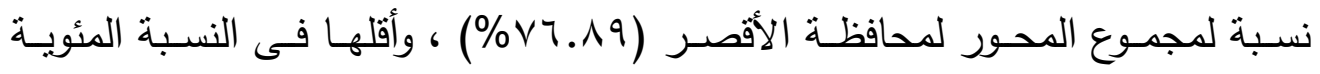

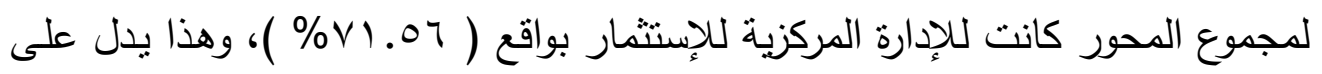

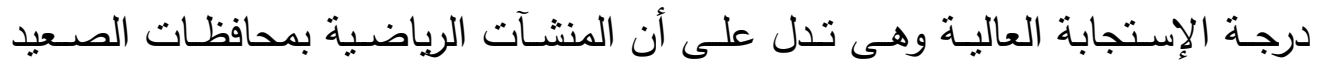

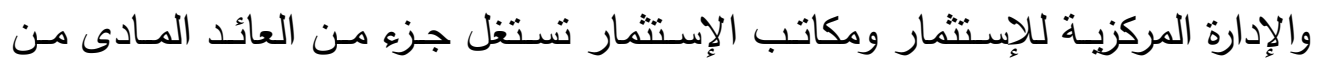
التمويل والموارد فى أعمال الصيانة والتجديدات بها، بالإضافة إلى أن هذه المنشآت

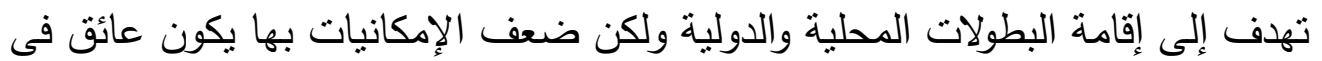
إقامة البطولات بالإضافة لعوامل أخرى مثل عدم وجود فنادق وأماكن كافية لإستضافة الإنة

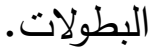


يتضـح أيضـاً مـن نتـائج الجـدول رقـم (0N) أنـهـ يجـب أن يكـون أعـداد

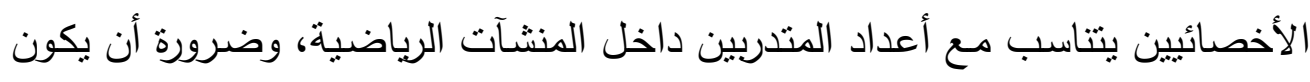

مديرى المنشآت متخصصين ولايهم رؤية لزيادة التمويل الذاتى.

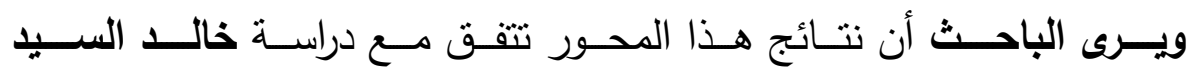

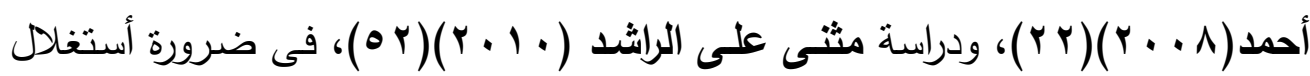

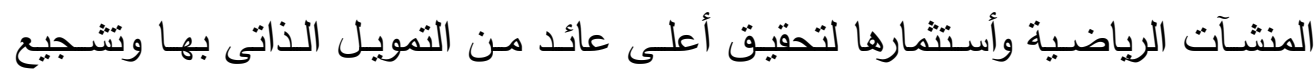

المستثرين وعمل التسهيلات اللازمة لإستغلال الأماكن الثاغرة بها.

كما يرى الباحث أن المصادر المقترحة لزيادة تمويل المنشآت الرياضية والثبابية

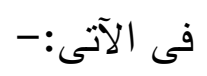

- إيبـار الملاعب بالأنديـة والمنشـآت الرياضـية عن طريـق مشــاركة الثـركات

$$
\text { المتخصصة وأستغلال الأماكن الثاغرة لتأجيرها. }
$$

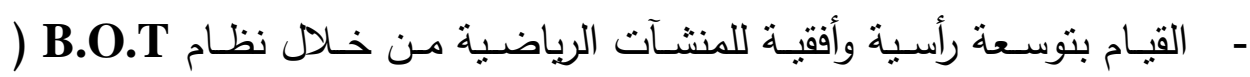

$$
\text { الخصخصة الجزئية) برعاية وزارتى الرياضة والثباب. }
$$

- ضـرورة دعم هذه المنشـآت وتجهيزهـا لإقامـة البطـولات المحلية والدوليـة بمـا

$$
\text { يتتاسب مع التطور الحديث حتى تحقق العائد المرجو منها. }
$$

المحور الثانى: دور التمويل الحكومى والأهلى كمصدر من مصادر التموئ لتمويل:-

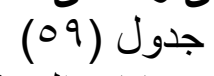

\begin{tabular}{|c|c|c|c|c|c|c|c|c|c|c|c|}
\hline الإستثم & زبة & & أسوان & محافة & لأقصر & محافظ & $\begin{array}{l}\text { (9 } \\
\text { (9 }\end{array}$ & & ع عوهاج & محافظ & العبــــــــــــــــار ات \\
\hline 5 & $\%$ & 5 & $\%$ & s & $\%$ & 5 & $\%$ & 5 & $\%$ & s & \\
\hline$\Lambda \varepsilon$ & १^... & rs & 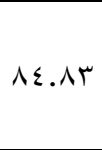 & $r \leqslant 7$ & NT.00 & KYV & VT.A & r.0 & $V \leq . Y q$ & rit & 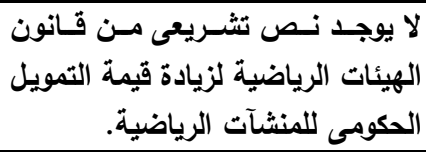 \\
\hline
\end{tabular}

الدرجة المقدرة والنسبة المئوية لاستجابات العينة في المحور الثاني دور التمويل

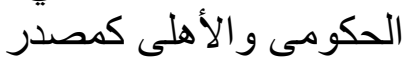

من مصنادر التمويل 


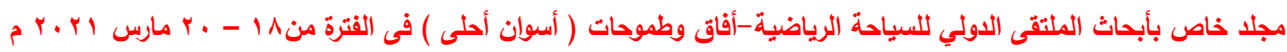

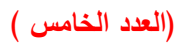

\begin{tabular}{|c|c|c|c|c|c|c|c|c|c|c|c|}
\hline ᄉ. & $\varepsilon \wedge .$. & $r \varepsilon$ & $\mathrm{V} 0.1 \mathrm{~V}$ & ris & $T V . T V$ & 110 & $v \cdot .90$ & TrV & $v \ldots$. & rq & 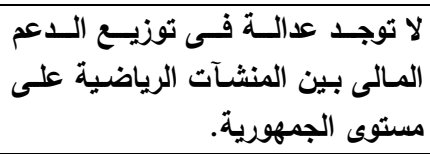 \\
\hline$V 4$ & ҮА... & $r \varepsilon$ & $71.9 \mathrm{~V}$ & r.. & $V 1.7 \varepsilon$ & $19 \mathrm{~V}$ & $V \varepsilon . V \leqslant$ & roo & $V 1 . \leqslant r$ & $r \ldots$ & 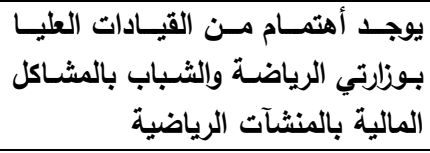 \\
\hline $7 \varepsilon$ & V & ru & $v 1 . . r$ & $r \cdot T$ & VO.TV & $r \cdot V$ & $V \varepsilon . M T$ & ror & $\vee \cdot . \leqslant \Lambda$ & rQ7 & 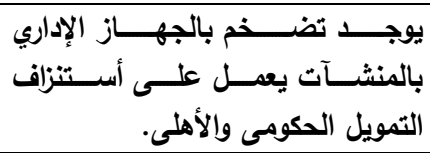 \\
\hline$v$. & VY... & ד & Tr. & $11 \Omega$ & VT.VT & rul & 79.71 & וTr & VY.AT & $r . T$ & 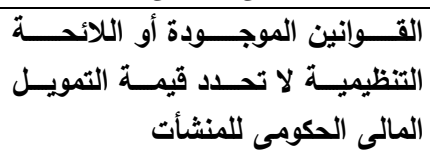 \\
\hline V & $\wedge \varepsilon \ldots$ & $\leqslant r$ & $70.0 \mathrm{r}$ & 19. & V9.7 & r19 & $\vee \vee . \neg A$ & r4q & VY.AT & $r . T$ & 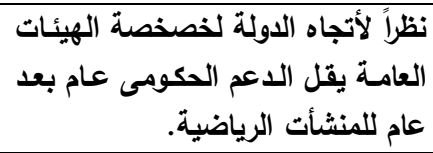 \\
\hline VY & $\wedge \ldots$ & $\varepsilon$. & Vo.AT & rr. & דוח. 1 & KYI & $V T . \leqslant Y$ & זדי & VV.TY & rTt & 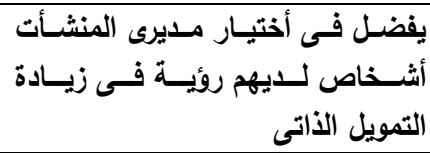 \\
\hline ᄉ. & V & rی & $V V . T \leq$ & TYE & V9.7 & r19 & VV.YT & rTV & VT.Tr & $r \cdot \Lambda$ & 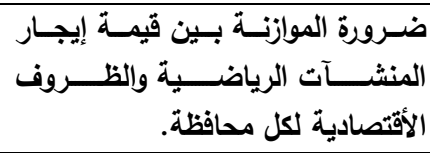 \\
\hline$V 7$ & $V Y \ldots$ & ד & $71.9 \mathrm{~V}$ & $r_{.}$. & $\vee \wedge .91$ & rIV & $V T . \leqslant Y$ & זדי & VT.MT & $r \cdot \Lambda$ & 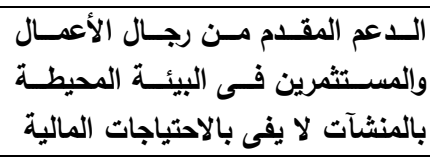 \\
\hline TVA & $V 1.07$ & Trt & VY.TE & $1 \wedge \wedge 1$ & $V 7.19$ & साI & $V \leq .9 Y$ & rT.r & $V Y .91$ & rVOT & مجموع المحور \\
\hline
\end{tabular}

يتضـح من الجدول السـابق (9 ه) أن النسبة المئوية لاستجابات عينة البحث

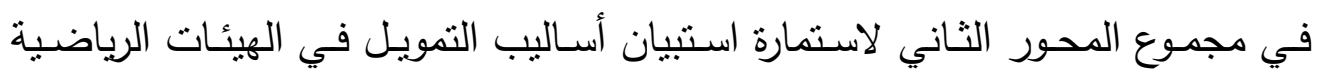

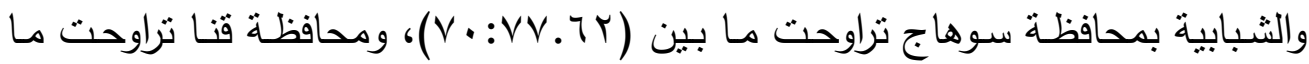
بـين (7.7人. 7.

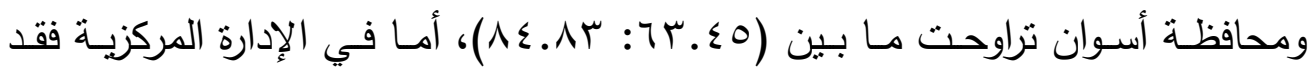

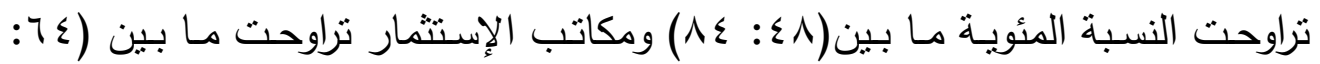

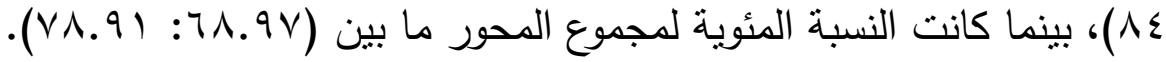

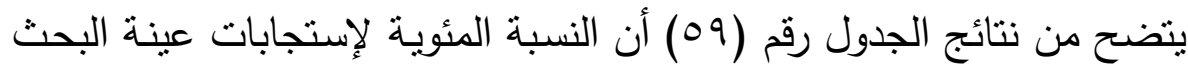

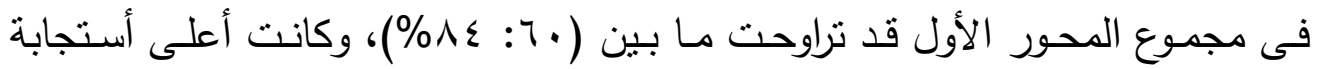


للعبارة رقم( (1) بمحافظة أسوان بأنه يجب أن تحدد أسعار خدمات المنشآت الرياضية على أسس وطرق علمية وكانت أعلى نسبة لمجموع محور التمويل في محافظة قنا

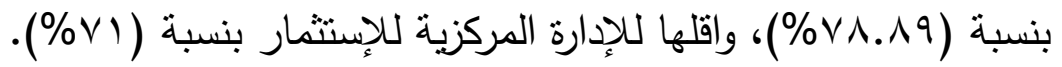

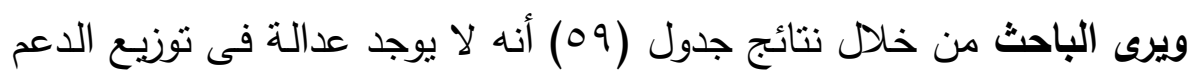

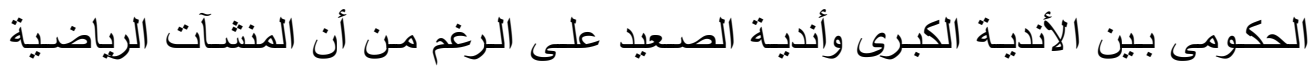

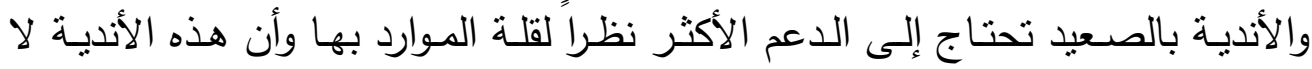

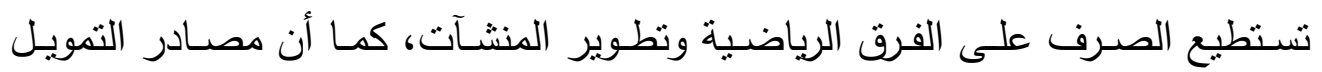

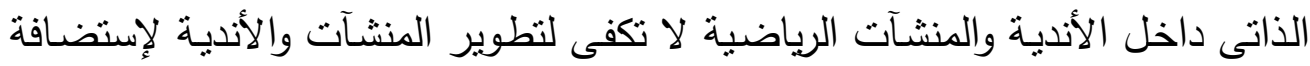
البطولات الكبرى.

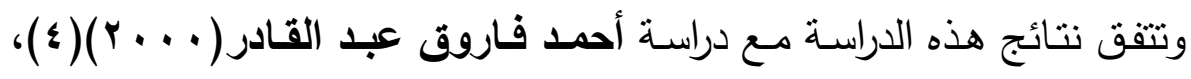

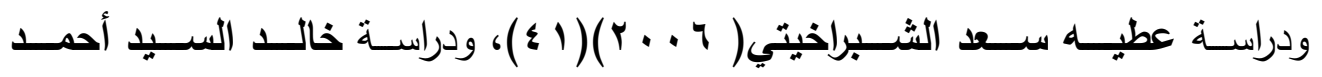

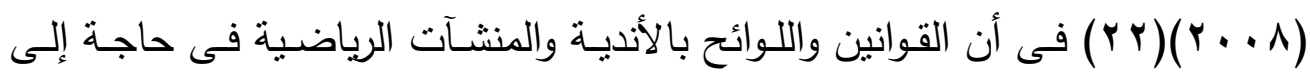
تعديل وتطـوير يســح بـإطلاق حريـة الإسـتمار لزيـادة التمويـل الذاتى لهذه الأنديـة والمنشآت الرياضية. ومن خـلال مـا سبق يـرى الباحث أن مـن المصـادر المقترحـة لزيـادة التمويـل هى:- وضع قوانين ولوائح تتظيمية ومالية لزيادة التمويل الأهلى والذاتى.

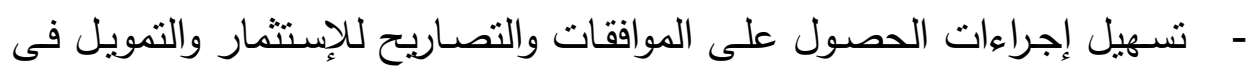
مجال المنشآت الرياضية. - إعادة توزيع الدعم المـالى الحكومى بين الأنديـة الكبيرة أو المنشآت الرياضـة الكبرى والأندية والمنشآت الرياضية الصغرى وخاصة محافظات الصعيد. - سرعة إصدار قانون الإستثمار فى الرياضة ليساعد على تبنى رجال الأعمال

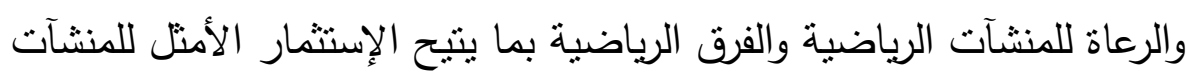
الرياضية خاصة أنها تحنل أماكن حيوية بالمحافظات. 
ويتضح من نتائج أستمارة دور التمويل الحكومى والأهلى كمصدر من مصادر

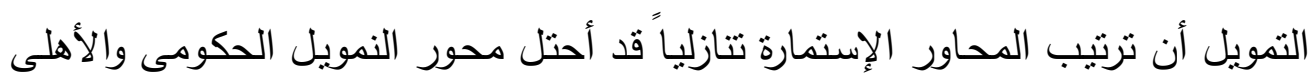

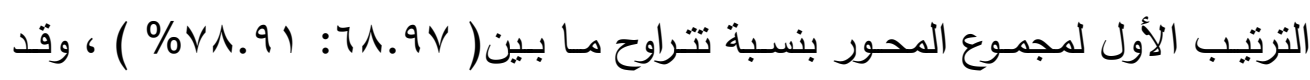

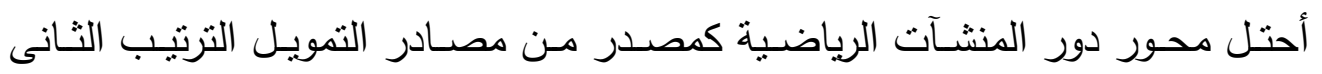

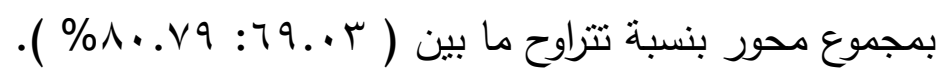

\section{الخطة المقترحة لتحسين أساليب التمويل في المنشأت الرياضية بأسوان}

\begin{tabular}{|c|c|}
\hline المحتوى & المحور \\
\hline تالتعنبر هذه الخطة أحد الخطوات والوسائل التى تحاول التعرف على كيفية تمويل & روئية الخطة \\
\hline 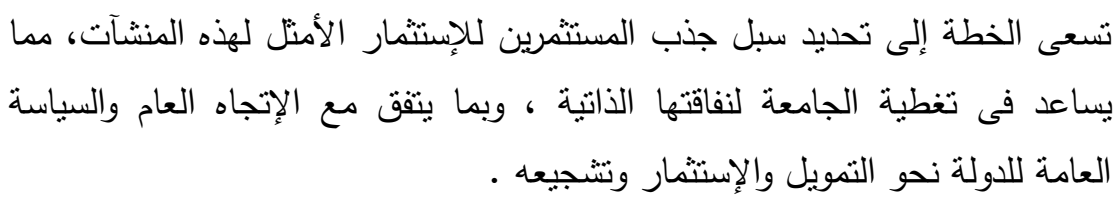 & رسالة \\
\hline
\end{tabular}




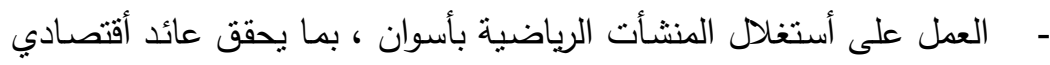
يمكن توظيفه في تطوير وتحسين المنشأت الرياضية.

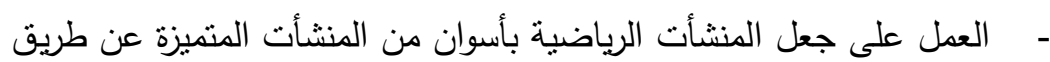
جذب رؤوس الأموال والمستثمرين وتغطية نفقاتها، وتحقيق ميزة تنافسية. - وضع المنثأت الرياضية بأسوان على خريطة المنافسة مع الجامعات العربية والعالمية. - - مضع إستراتيجية شاملة لأستثمار المنثأت الرياضية بأسوان.

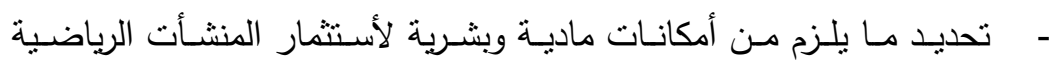

فتح فرص الاستثمار المحلي والأجنبي للمنشآت الرياضية بأسوان لما تتمتع به الجامعة من موقع جغرافي متميز . - تخفيف العبء على الدولة والاتجاه إلى الاعتماد على التمويل الذاتي بدلاً من الاعتماد على الدعم الحكومي بشكل كامل. - نشر الثقافة التمويلية والأستثمارية للمنشأت الرياضية بأسوان . - الاهتمام بإعداد برامج وأنشطة في مختلف الرياضات لجذب المستثمرين لأستثمار

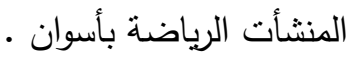

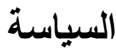

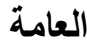
- دعم وتطوير الأماكن الثاغرة بالمنشأت الرياضية وأستغلالها في عملية الأستثار . - نطوير الجوانب الإداريـة والجوانب الفنية والجوانب التخطيطية والتنظيمية للعاملين للخطة

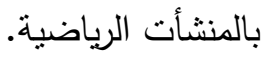


تابع الخطة المقترحة لأستثمار المنثأت الرياضية بجامعة أسوان

\begin{tabular}{|c|c|}
\hline المحتوى & المحور \\
\hline 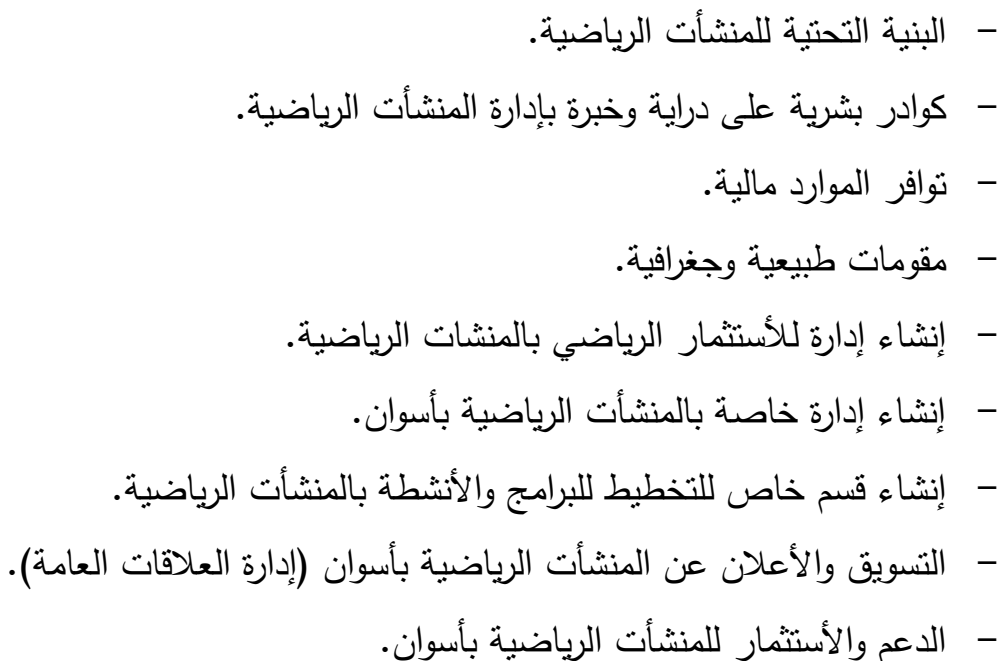 & مقومات \\
\hline
\end{tabular}


- - التخطيط السليم والعلمي لأستتمار المنشأت الرياضية بأسوان.

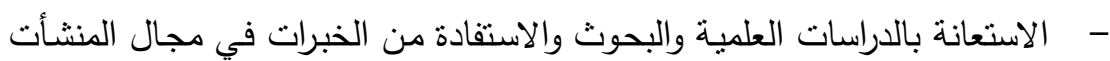

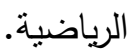
- - وضـع خطـة لإعداد كوادر بشـرية متخصصـة في مجـال التمويـل والأستنثمار

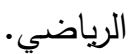
- - استقام ودعوة الخبراء المتخصصين في مجال الأستثمار للاستفادة من خبراتهم العلمية والعطلية. وضـع خطـ للاسـتنمار قصـير الأجـل وطويـل الأجـل لأسـتغلال المنشـأت

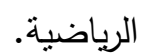
- - التركيز على صناعة السوق التتافسية بين المستثرين لتحقيق أقصى استفادة ممكنة في من المنشأت الرياضية.

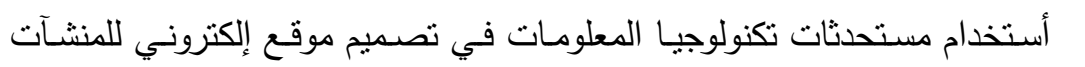

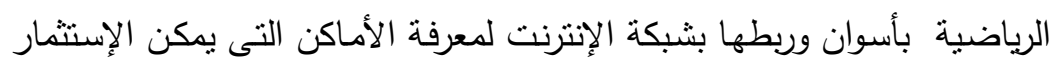
فيها ، مع توفير كافة المعلومات عن المنشآت الرياضية.

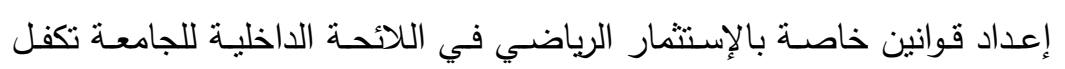
تحقيق الإستثمار الأمتل لهذه المنشآت. - - العمل على مرونـة الخطط الموضوعة لأستنمار المنشآت الرياضية ، ومشـاركة الإسية العاملين بالمنشآت الرياضية فى عملية التخطيط ، مما يساعد على التنفيذ الجيد للخطط والبرامج الموضوعة.

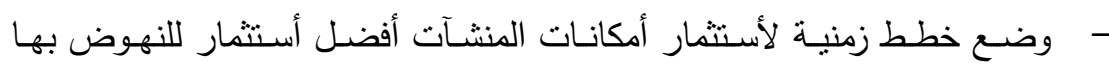
وتحديثها وذلك من خلال جدول زمنى.

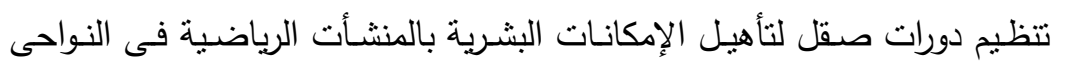
الإسنثمارية . - العمل على عقد مؤتمرات وندوات تجمع رجال الرياضة والأستثمار سعياً لترسيخ

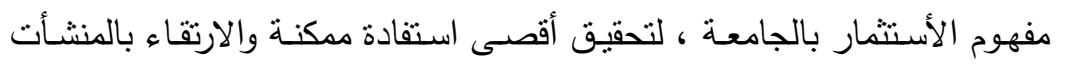
الرياضية بالجامعة. - - ـ إزالة المعوقات أمام المستثمرين وتسعيل الإجراءات الإدارية والفنية.
آليات تتفيذ

الخطة 


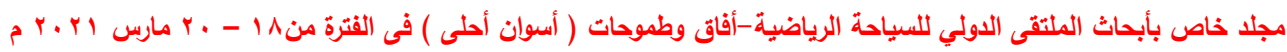

- إعداد نقارير بصفة دوريـة ومستمرة عن الوضـع الحالي (الإيجابيات والسلبيات) للمنشأت الرياضية وما تحتاج إليه المنشأت من أمكانات لتوفيره.

ا- تتم المتابعة باستخدام الأسلوب العلمي للتعرف على نقاط القوة ونقاط الضـف

ومعرفة أوجه القصور حيث يمكن أن بستدل على مدى نجاح الخطة من خلال: • إنشاء لجنة للمتابعة والتقييم تختص بمقارنة النتائج بالأهداف الموضوعة. 
• مدى مناسبة الإمكانات والمنشأت وعددها لمنطلبات وإحتياجات الأفراد والمستقيدين •

r- العمل على حل المشكلات التي تواجه عملية التتفيذ أول بأول. جامعة أسوان.

\section{الخاصة بأساليب التمويل في الهيئات الرياضية والثبابية :}

أ- دور المنشآت الرياضية كأحد مصادر التمويل في الهيئات الرياضة والثبابية:

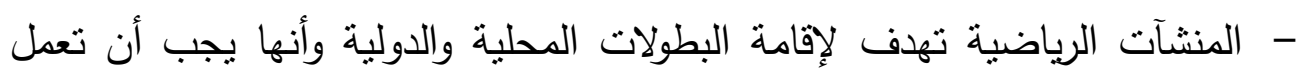
على الاستثمار المالي والبشري لموارد البيئة المحيطة. - المنشآت الرياضية تستغل جزء من العائد المادي لأعمال الصيانة والتجديدات. - اللوائح المنظمة للعمل بالمنشآت لا تساعد على جذب المستثمرين. - لا يوجد إداريون متخصصون في تسويق المنشآت الرياضية وان أعداد الأخصائيين الرياضيين لا يتتاسب مع أعداد المتدربين داخل المنشآت الرياضية.

\section{ب- دور التمويل الحكومي والأهلي كمصدر من مصادر التمويل :}

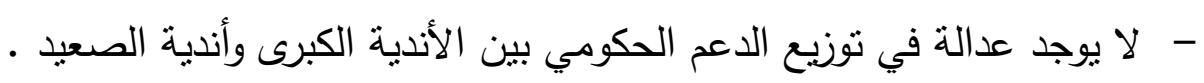

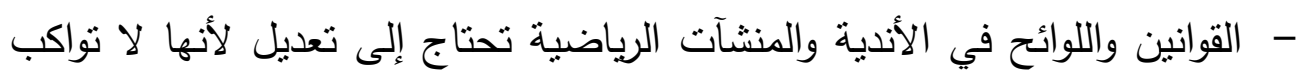
التطور الحادث في الرياضة والنطور في صناعة الرياضة وإطلاق حرية الاستثمار

والتسويق الرياضي ووضع لوائح وقوانين تساعد على زيادة التمويل الذاتي.

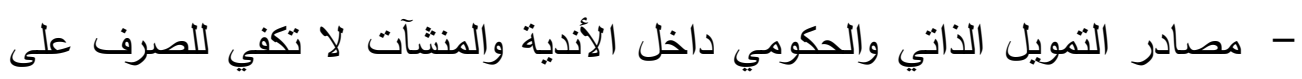
صيانة المنشآت والنطوير المستثر والتمرين في المنشآت لمواكبة التطور الحادث في الرياضة. 
- استتتج الباحث من خلال نتائج أستمارة دور التمويل الحكومي والأهلي كمصدر من مصادر التمويل أن ترتيب المحاور الإستمارة تتازليا مَقد أحتل محور التمويل دوريل

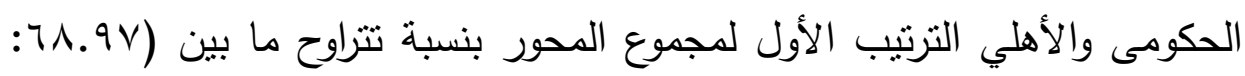

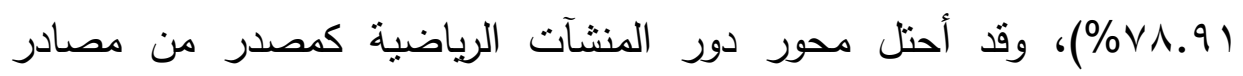
التمويل الترتيب الثاني بمجموع محور بنسبة تتراوح ما بين ( r. ب.79 :

$$
\begin{aligned}
& .(\% \wedge \text {. . v } 9 \\
& \text { التوصيات:- }
\end{aligned}
$$

ا- ضرورة تطبيق الخطة المقترحة لتمويل المنشآت الرياضية والثبابية والتي توصلت

$$
\text { إليها الدراسة على جميع المؤسسات الرياضية. }
$$

ץ- ضرورة العمل على استثمار المنشآت الرياضية والثبابية الواقعة في نطاق المحافظات وخاصة الصعيد، واستنمار مرافقها أو تأجيرها وتسويقها محليا وعالميا وخاصة لما تملكه محافظات الصعيد من مواقع منميزة تساعد على جذب مرنب

$$
\text { الاستثمار والسياحة. }
$$

r- يجب أن تعمل الدولة على تشجيع رجال الأعمال والمستثرين للاستثمار في الإني الأندية والمنشآت الرياضية والثبابية مع إعطائهر التسهيلات اللازمة وتهيئة مناخ التمويل والاستثمار لجذب رؤوس الأموال الداخلية والخارجية للاستثمار في

$$
\text { المنشآت الرباضية. }
$$

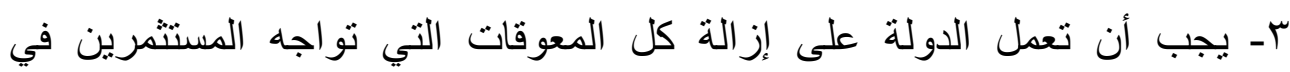

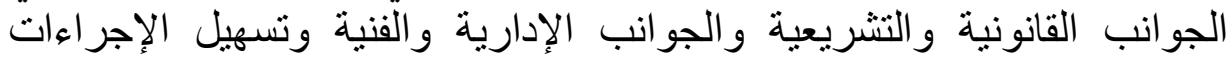

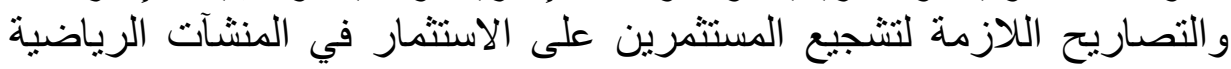
و والثبابية. 


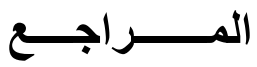

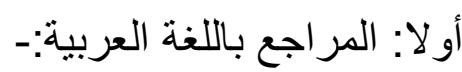

1 - أحمد رشاد محمد: إستراتيجية مقترحة لتسويق البطولات المبارزة، رسالة ماجستير غير منشورة، كلية التربية الرياضية، جامعة بنها، V . . آم .

r- أحمد فتحي الأفندي: الإدارة الإستراتيجية للتسويق بالاتحادات الرياضية الدصرية،

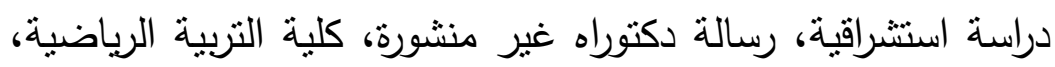

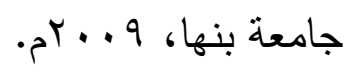

r- أثرف محمود حسين: معوقات الإستثمار في المجال الرياضي في ج•م•ع، رسالة

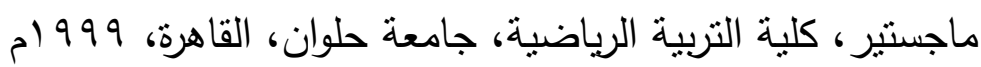

ع - أثرف محمود حسين: الأزمات الاقتصادية فى الهيئات الرياضية الأهلية، رسالة

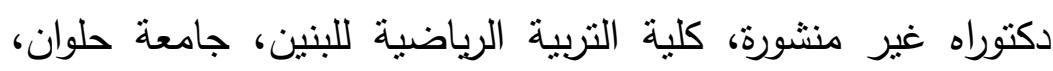

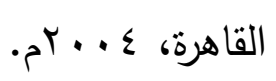

๑- إيمان زكي محمد، يحيي فكرى محمد: تقويم التمويل الذاتي فى الاتحادات الرياضية الأولمبية، الدصرية، مجلة نظريات وتطبيقات كلية التربية

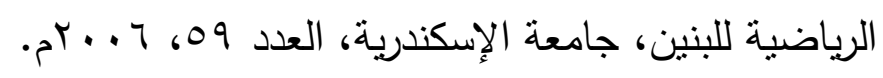

T- إيمان محمد أحمد: إستراتجية مقترحة لاستثمار أنثطة الاتحاد المصري لكرة اليد بجمهورية مصر العربية، رسالة دكتوراه غير منشورة، كلية التربية

$$
\text { الرياضية، جامعة أسيوط، } 7 \text { +. بام. }
$$

V- المجلس القومي للرياضة: لائحة القواعد المنظمة لإدارة وتنشغيل المنشآت

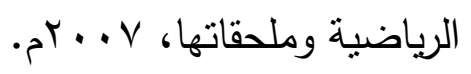

1- المجلس القومي للرياضة: لائحة النظام الأساسي للأندية الرياضية، م ـ. بم. 
9 - جمال محمد على: الحديث فى الإدارة الرياضية، دار الفكر العربي، القاهرة،

$$
\cdot r^{r} \cdot 9
$$

• ا-حسام حسن شحاته: نظام مقترح لخصخصة بعض الأندية الرياضية في جمهورية مصر العربية، رسالة ماجستير، كلية التربية الرباضية،

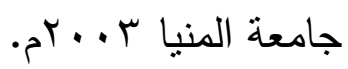

1ا-حسام حسن شحاته: نظام مقترح للاستثمار في بعض الأندية الرياضية المصرية، رسالة دكتوراه، كلية التربية الرياضية، جامعة الإسكندرية،

$$
\cdot \sin
$$

r ا - حسام رضوان كامل: اقتصاديات الاتحادات الرياضية الأولمبية المصرية، دراسة تحليلية، رسالة دكتوراه غير منشورة، كلية التربية الرياضية، للبنين،

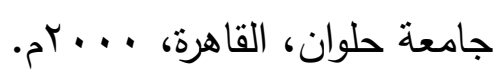

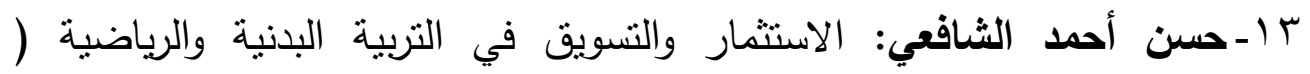
الموسوعة العلمية لاقتصاديات الرياضة)، دار الوفاء للطباعة والنشر ، النش

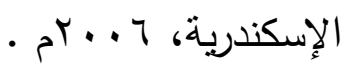

ع ا-حسن أحمد الشافعي: الخصخصة الإدارية والقانونية في التربية البدنية والرياضية، مكتبة الإشعاع الفني، الإسكندرية، r + . rم •

10 ـ حسن أحمد الثاقعي: دراسات الجدوى والمشروعات الصغيرة في التربية البدنية والرياضية، دار الوفاء للطباعة والنشر، الإسكندرية، ج ـ . rام •

7 ا ـ حليمة زيل محمد: تقييم الإستثمارات القطاع الخاص في مجال التعليم واتجاهات

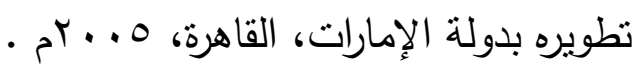


IV مصر العربية، رسالة ماجستير غير منشورة، كلية التربية الرياضية

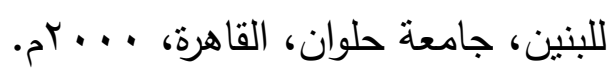

1 1 ـ خالد السيد أحمد: تقويم مصادر تمويل الأندية الرياضية لمحافظة الثرقية، رسالة ماجستير، غير منشورة، كلية التربية الرياضية للبنين ، جامعة بنها،

$$
\cdot{ }^{2}+\cdots
$$

9 ا -خالد طلعت السيد: المشكلات التمويلية التي تواجه إدارات النشاط الرياضي ببعض الأندية الرياضية، رسالة دكتوراه، كلية التربية الرياضية للبنين،

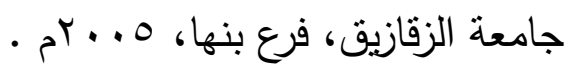

• • زكي محمد حسن: المنشآت الرياضية، طا، دار الكتاب الحديث، القاهرة،

$$
\cdot r^{r} \cdot 11
$$

ا آ-سامي محمد السيسي: أثز التحرير الاقتصادي في مجال الاستثمار في القطاع الزراعي المصري، رسالة دكتوراه غير منشورة، كلية الزراعة، جامعة

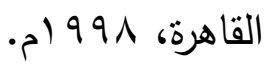

Y Y - سعد أحمد شلبي: أسس إدارة التسويق الرياضي، المكتبة العصرية، المنصورة،

$$
\text { . م } 0
$$

r T-سمير عبد الحميد: إدارة الهيئات الرياضية، النظريات الحديثة وتطبيقاتها، منشأة

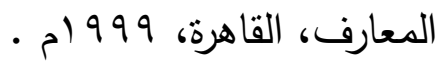

ع r-سمير محمد عبد السلام: جدوى الإستثمار الرياضي في مجال السباحة، رسالة

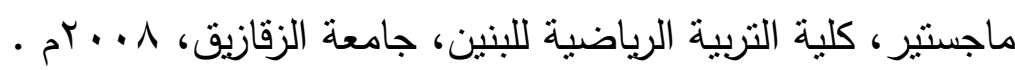


هr-سيد محمد السيد: تمويل الرياضة في القطاع الأهلي، دراسة تحليلية، رسالة

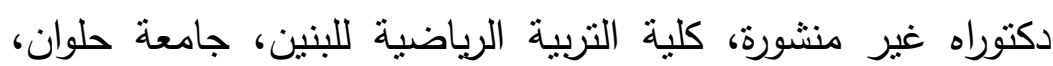

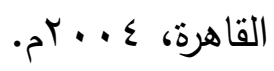

جr-شريهان يحيي محمد: تفعيل آليات جذب رجال الأعمال للاستثمار في المجال الرياضي، رسالة ماجستير غير منشور، كلية التربية الرياضية،

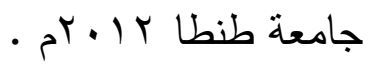

V עياء الدين محمد العزب: محاضرات في المنشآت الرياضية الدورة الأولي

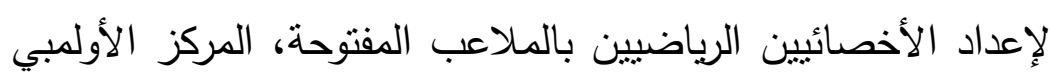

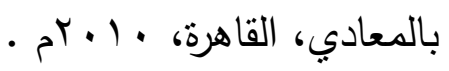

^r - عبد الغفار حنفي، رسمية قراقص: أساسيات الإستثمار والتمويل، مؤسسة شباب

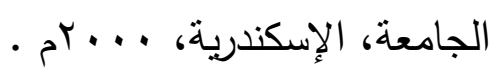

9 - عطيه سعد الشبراخيتي: استثمار الأندية المصرية لنشاط رياضة كرة القدم اقتصاديا، رسالة ماجستير، كلية التربية الرياضية، جامعة الزقازيق،

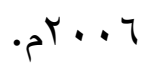

• r- علي عباس السندواي: تحليل الوضع الراهن للاستثمار في الأندية الرياضية.

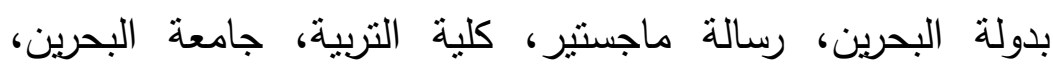

$$
\cdot r
$$

اس- عمرو أحمد الجمال: التمويل وعلاقته باتخاذ القرار فى بعض الاتحادات الرياضية بجمهورية مصر العربية، رسالة دكتوراه غير منشورة، كلية

$$
\text { التربية الرباضية للبنين، جامعة حلوان، القاهرة، } 999 \text { (م. }
$$


r Y ـ عمرو محمد إبراهيم، حازم كمال الدين: أساليب تسويق مدراس السباحة فى

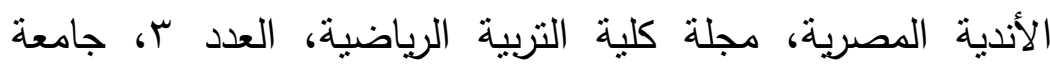

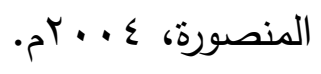

بr- فريد شوشة: الإدارة الإستراتيجية، دار النهضة العربية، القاهرة، 999 1. ع ـ كمال درويش، أشرف عبد المعز : المنظمات الرياضية الأهلية (المفهوم، التاريخ،

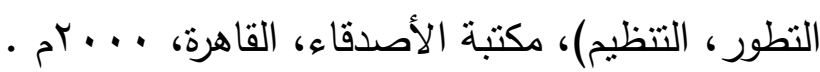

هـ-كمال عبد الجابر عبد الحافظ: خطة مقترحه لتسويق القرية الأولمبية بجامعة أسيوط فى ضوء الفجوات التسويقية، مجلة كلية التزبية الرباضية،

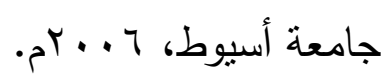

דب كمال عبد الرحمن درويش، محمد صبحي حسانين: موسوعة متجهات الرياضة

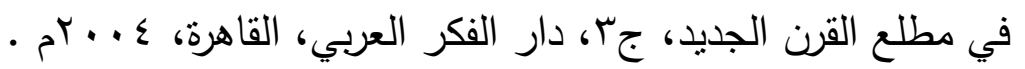

Y - ماهر محمد السيد عطيه: واقع التسويق الرياضي بالأندية الرياضية، رسالة

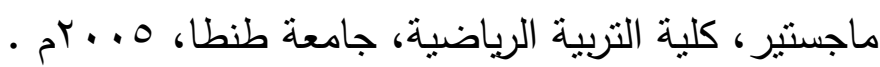

^ץ-ـ مثني علي عريود الراشد: إستراتيجية مقترحة لنطوير التسويق الرياضي بدولة الكويت، رسالة ماجستير غير منشورة، كلية التربية الرياضية، جامعة

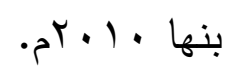

q廿-محسن أحمد الخضري: المناخ الإستتماري المستهدف، الإدارة واستراتيجيات

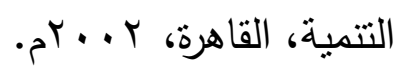

• ـ ـ محمد رجب جبريل: الخطة الإستراتيجية لتسويق البطولات والمباريات الرياضية، رسالة دكتوراه غير منشورة، كلية التربية الرياضية للبنين، جامعة الإبنة

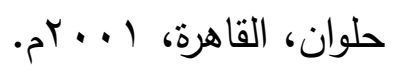


اء ـ محمد عبد العظيم محمود: خطة مقترحة لإدارة المؤسسات الرياضة وفقاً للأهداف

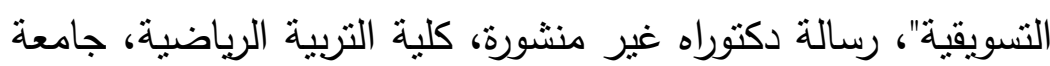

$$
\text { أسيوط، } 7 \text { + . r.م. }
$$

ץ - مسعد سيد عويس: الأدوار المستخدمة والمستحدثة للأنشطة الرياضية، دراسة

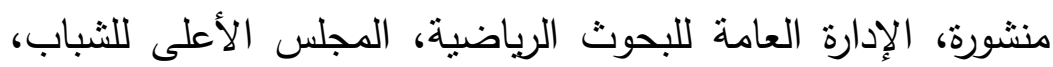

$$
\text { ج. }
$$

ץ؟ ـ معتز مصطفي عبد الجواد: مدخل إداري معاصر لإستثمار المؤسسات الرياضية، رسالة دكتوراه، كلية التربية الرياضية للبنات، جامعة الإسكندرية، الإسية

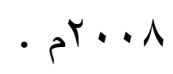

§ ـ - معجم اللغة العربية: المعجم الوجيز، المطابع الأميرية، القاهرة، و99 ام • 0ـ-منير إبراهيم هندي، السعيد محمد لبدة: الإدارة المالية كلية التجارة، جامعة

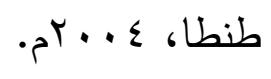

Tـ ـ نائل البابلي، إبراهيم محمد: موسوعة الإستثمار، دار الفكر العربي، القاهرة،

$$
\text { . }) 99 \leq
$$

V V - هثام عبد الحفيظ السباعي: دور نظم المعلومات في دعم مناخ الإستثار،

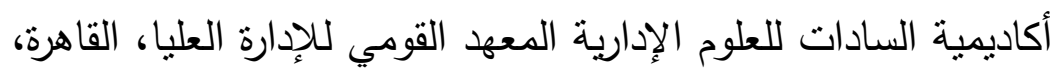

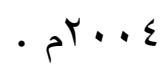

1ـ-وزارة الإستثمار: قانون ضمانات وحوافز الإستثمار ولائحته التنفيذية، القاهرة،

$$
\text { - P) } 99 \leq
$$

9 ـ يحيب بلر مبارك فاتح: إستراتيجية مقترحة لجذب رؤوس الأموال للإستثمار في الأندية الرياضية الكويتية، رسالة ماجستير، كلية التربية الرياضية

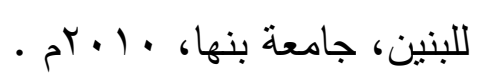




\section{ثنانياً: المر اجع باللغة الإنجليزية:}

50- Athanasios Kriemadis,: Stratigic Marketing planning in greek professional sports, 16 th Easm conference " Management the Heart of sport" 10- 13. September, Heidelberg, Germany, 2008.

51- Beniot seguin, Kenneth Teed and Norman O. Reilly: National sports organizations and, Sponsrship: An identifiction of the best practices int . J . Sport Management and Marketing, Vol 1, Nos / 12/ 2005.

52- Bill Gerrard: A resource -utilization model of organizational efficiency in professional sports teams, JSM, 17 (3) July, 2003.

53- David, Larimore \& George, Chitiyo: Non Economic Societal Impact of Intercollegaiat Athletics, The Sport Journal, Volume 10 Number 2, Spring, published by United States Sport Academy, 2007.

54- Kenet, P.A, and Athers: Market segmentation in the sport indury, international. Sort Journal (1) refs 16, (1997).

55- Mclean, D. J., Jonson, R. C. A.,: Techniques for Aqtioning public recreation services journal for park and recveation, Administration champaign, 111, 15 (3) Refsm 27, 1997. 